\title{
Concentrated Capital Losses and the Pricing of Corporate Credit Risk - Online Appendix
}

\section{Citation}

Siriwardane, Emil N. "Concentrated Capital Losses and the Pricing of Corporate Credit Risk Online Appendix." Harvard Business School Working Paper, No. 16-008, July 2015.

\section{Permanent link}

http://nrs.harvard.edu/urn-3:HUL.InstRepos:17527684

\section{Terms of Use}

This article was downloaded from Harvard University's DASH repository, and is made available under the terms and conditions applicable to Open Access Policy Articles, as set forth at http:// nrs.harvard.edu/urn-3:HUL.InstRepos:dash.current.terms-of-use\#OAP

\section{Share Your Story}

The Harvard community has made this article openly available.

Please share how this access benefits you. Submit a story.

\section{Accessibility}




\section{Concentrated Capital Losses and the Pricing of Corporate Credit Risk - Online Appendix}

Emil N. Siriwardane

Working Paper 16-008 


\section{Concentrated Capital Losses and the Pricing of Corporate Credit Risk - Online Appendix}

Emil N. Siriwardane

Harvard Business School

Working Paper 16-008 


\title{
Concentrated Capital Losses and the Pricing of Corporate Credit
}

\section{Risk}

\section{Online Appendix}

\author{
Emil Siriwardane*
}

July 17, 2015

\begin{abstract}
This is the online appendix to "Concentrated Capital Losses and the Pricing of Corporate Credit Risk". In this appendix, I provide additional stylized facts about the CDS market regarding: (i) the size of the market, (ii) the concentration of net buyers and sellers within each reference entity, (iii) the commonality of net buyers and sellers across reference entities, (iv) who purchases and sells protection, (v) the network structure of the CDS trading network, and (vi) the role of dealers in the CDS market. In addition, I discuss why the role of dealers as prime brokers does not impact the stylized facts and results presented throughout the paper.
\end{abstract}

*Affiliation: Harvard Business School and the Office of Financial Research, U.S. Department of Treasury. E-mail: esiriwardane@hbs.edu. 


\section{Additional Stylized Facts about Credit Default Swap Markets}

\subsection{Total Size of the CDS Market}

\subsubsection{Motivating Discussion}

Much of the data on CDS markets documents the size of the market according to gross notional. It is well-known that gross notional can be misleading. To illustrate, consider a simple example involving Hedge Fund $A$ and Hedge Fund $B$. Suppose further that in one transaction, Hedge Fund $A$ sells a CDS on GE for $\$ 100$ million to Hedge Fund $B$ in one transaction. In a separate transaction, Hedge Fund $B$ sells $\$ 100$ million in CDS on GE to Hedge Fund $A$. The true amount of credit risk transferred in this case is actually zero, but the gross notional between the two counterparties is $\$ 200$ million.

To illustrate further, consider the following depiction of CDS positions (across all reference entities) in a fictional market with only three counterparties, denoted by $\mathrm{A}, \mathrm{B}$, and $\mathrm{C}$ :

Figure 1: Fictional CDS Exposure Network

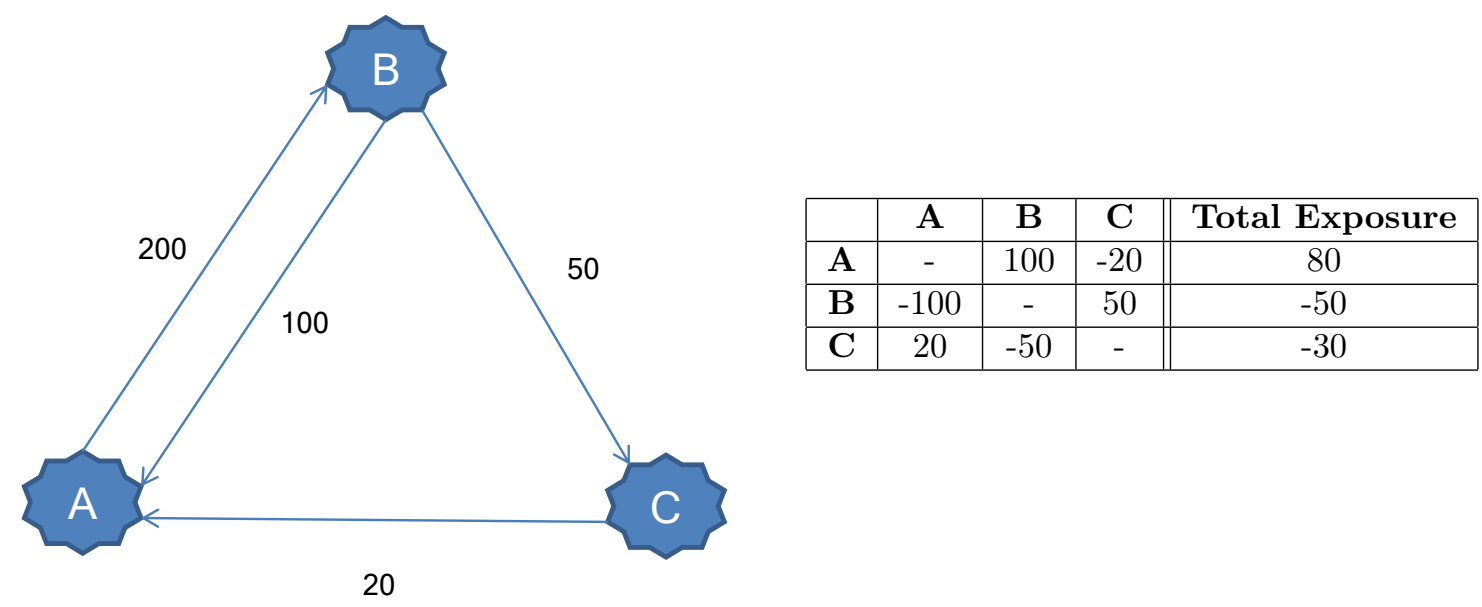

Notes: The figure on the left illustrates a fictional CDS network of exposures amongst three counterparties: $A, B$, and $C$. An arrow pointing from $A$ to $B$ means that $A$ sells CDS insurance to $B$. All quantities are in millions of dollars. The table on the right summarizes net exposures depicted in the figure. In the left partition of the matrix, entry $(i, j)$ represents how much insurance $i$ sells to $j$. The right partition of the matrix is the total net exposure of each counterparty, where positive values indicate a net seller.

In this setting, it is clear that there is a total of $\$ 80$ million of dollars of net credit risk being transferred. $A$ is a net seller of $\$ 80$ million, and $\$ 50$ million of this protection ultimately ends up with $B$, whereas $\$ 30$ million ends up with $C$. This sits in stark contrast with the outstanding gross notional in this fictional environment, which is $\$ 370$ million.

The situation becomes even more complicated when we add additional reference entities. To see why, suppose now there are two reference entities, GE and Apple. In addition, consider the following set of exposures: 
Table 1: Summary of Exposures with Two Reference Entities: Example 1

\begin{tabular}{|ccc|c|}
\hline \multicolumn{1}{c|}{} & \multicolumn{3}{c|}{ Reference Entity } \\
\cline { 3 - 4 } & & GE & AAPL \\
\cline { 2 - 4 } Counterparty & A & 80 & -10 \\
\cline { 2 - 4 } & B & -50 & 25 \\
\cline { 2 - 4 } & C & -30 & -15 \\
\hline
\end{tabular}

Notes: The table above depicts a second fictional situation in which there are three counterparties (A,B and C) and two reference entities (GE and AAPL). Entries in the table capture how much each counterparty has net sold in protection (\$mm) for each reference entity.

The exposure to GE are the same as Figure 1, but now we have additional exposures to Apple. For instance, Counterparty A has bought $\$ 10$ million in protection on Apple. It is easy to see that the overall exposures for Counterparties $\mathrm{A}, \mathrm{B}$, and $\mathrm{C}$ are $\$ 70,-\$ 25$, and $\$-45$ million, respectively. Here (and for the remainder of the paper), I assume a net selling position is a positive value.

How much credit risk is being transferred in this scenario? One potential answer is $\$ 70$ million, since Counterparty A has sold $\$ 70$ million (across both reference entities) to both B and C. Another potential answer is $\$ 105$ million. To see where this number comes from, notice that $\$ 80$ million has been transferred for GE and $\$ 25$ of credit risk has been transferred for Apple; thus, in total there is $\$ 105$ million transferred. To define these potential metrics in a more general setting, denote the net sold position of counterparty $c$ on reference entity $r$ at time $t$ by $N S_{c r t}$, where again negative values indicate Counterparty $c$ buys protection on $r$. The two aforementioned measures of overall credit risk transfer are then:

$$
\begin{aligned}
C R T_{t}^{C} & =\frac{1}{2} \sum_{c=1}^{C}\left|\sum_{r=1}^{R} N S_{c r t}\right| \\
C R T_{t}^{R} & =\frac{1}{2} \sum_{r=1}^{R} \sum_{c=1}^{C}\left|N S_{c r t}\right|
\end{aligned}
$$

where $C$ is the total number of counterparties in the economy and $R$ is the total number of reference entities. In the example from Table $1, C R T_{t}^{C}=70$ and $C R T_{t}^{R}=105$. I assert that $C R T_{t}^{R}$ is the more natural measure of credit risk transfer in CDS markets. The reason is easy to see in an alternative example, which I depict below:

Table 2: Summary of Exposures with Two Reference Entities: Example 2

\begin{tabular}{|ccc|c|}
\hline \multicolumn{1}{c}{} & \multicolumn{3}{c|}{ Reference Entity } \\
\cline { 3 - 4 } & & $\mathbf{1}$ & $\mathbf{2}$ \\
\cline { 2 - 4 } Counterparty & $\mathbf{A}$ & 80 & -80 \\
\cline { 2 - 4 } & $\mathbf{B}$ & -50 & 50 \\
\cline { 2 - 4 } & $\mathbf{C}$ & -30 & 30 \\
\hline
\end{tabular}

Notes: The table above depicts a second fictional situation in which there are three counterparties (A,B and C) and two reference entities (GE and AAPL). Entries in the table capture how much each counterparty has net sold in protection ( $\$ \mathrm{~mm})$ for each reference entity.

In this case, each counterparty has a net zero position (i.e. $C R T_{t}^{C}=0$ ), but this does not mean there is no credit risk being transferred via CDS. Indeed, Counterparty B and C transfer $\$ 80$ million of the GE's credit risk to Counterparty A. Similarly, Counterparty A transfers $\$ 80$ million of Apple's credit risk to 
Counterparties B and C. Even though each person is net zero, there is still $\$ 160$ million in overall credit risk being transferred (i.e. $C R T_{t}^{R}=160$ ). At a higher level, the metric $C R T_{t}^{C}$ implicitly assumes a correlation structure for defaults; that is, $C R T_{t}^{C}$ assumes defaults are perfectly correlated. $C R T_{t}^{R}$ is not the necessarily the perfect solution, but it is easy to see $C R T_{t}^{R}$ is analogous to the face value of outstanding debt in corporate bond markets. For this reason, I choose it as my preferred measure of the "net notional outstanding" or the "size of the CDS market". Nonetheless, $C R T_{t}^{C}$ is informative about the degree of credit risk sharing that occurs in these markets. To see why, define the following ratio:

$$
C R S_{t}=\frac{C R T_{t}^{C}}{C R T_{t}^{R}}
$$

It is straightforward to prove that $0 \leq C R S_{t} \leq 1$. When $C R S_{t}=0$, then each counterparty in the economy has an overall net zero position. Conversely, when $C R S_{t}=1$, it means one counterparty bears the credit risk for all reference entities.

\subsubsection{Quantifying the Size of CDS Markets}

Figure 2 plots the amount of credit risk being transferred according to a variety of filters: (i) all swaps, (ii) all swaps excluding those written on MBS and tranched swaps, and (iii) the total amount of credit risk transferred for the top 100 names. I then repeat the same three filters on swaps that are only U.S. reference entities. Again, the process of classifying a reference entity as a U.S. firm is detailed in Data Appendix Section 2.3. 
Figure 2: Net Notional Outstanding in CDS Markets

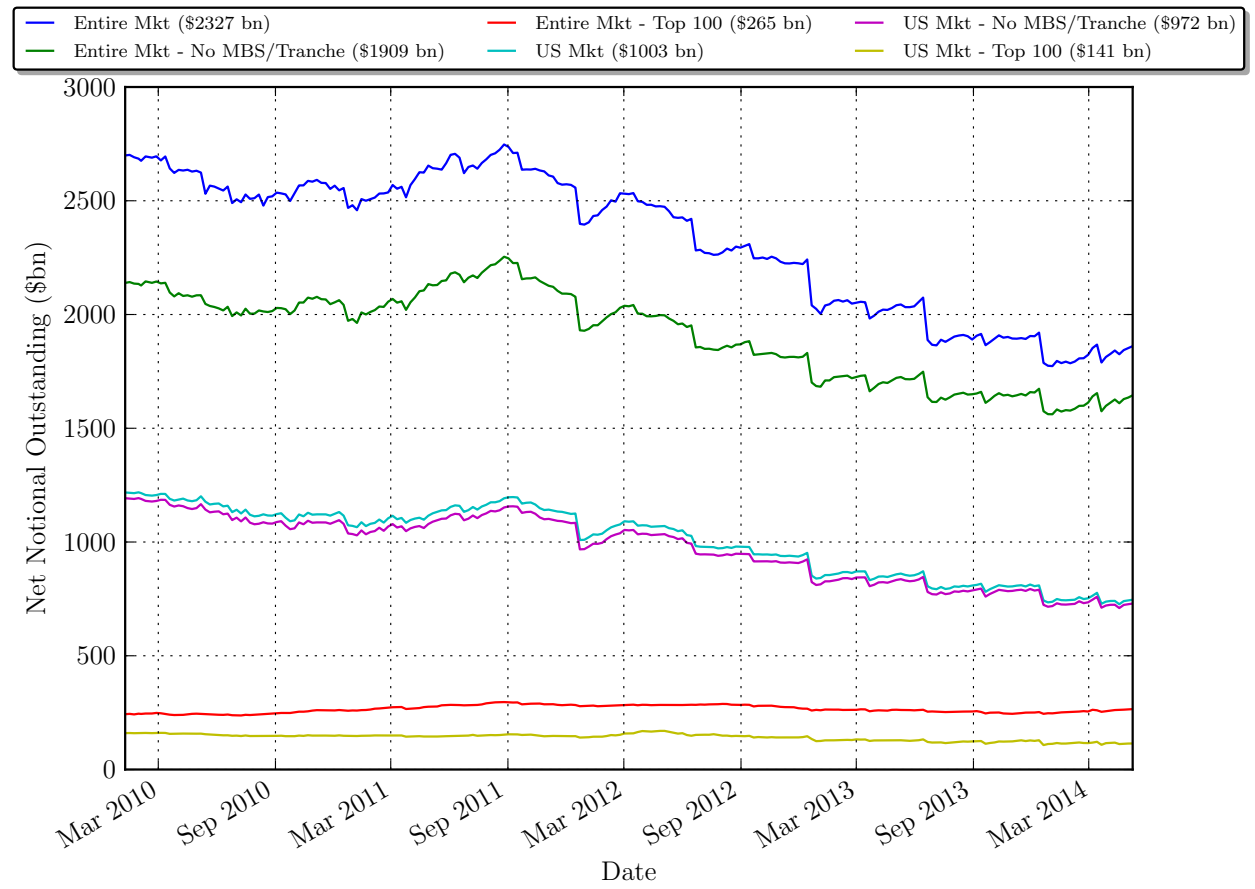

Notes: This figure plots the net notional outstanding in CDS markets. The total net notional outstanding is as defined in the second line of Equation (1). This statistic is plotted for: (i) using the entire dataset, (ii) using the entire data set, but excluding CDS written on MBS and tranches, (iii) the top 100 reference entities in the entire market. I then repeat the same set of filters for U.S. reference entities only, where a U.S. reference entity is refined according to the methodology in the Data Appendix. In the legend, the numbers in parenthesis indicate time-series averages.

To compute a single estimate for the size of the U.S. market, I take the average of the entire market (blue line) that includes my entire dataset, and reference entities that I can definitely classify as U.S. only (turquoise line). A more conservative estimate of the size of the U.S. market would simply be the latter.

Figure 3 plots the gross amount outstanding according to the same set of filters. Naturally, the gross outstanding is much higher than the net outstanding for the entire market. The gross outstanding for U.S. CDS markets is, on average, roughly $\$ 24$ trillion. $^{1}$ Figure 2 further suggested that the size of the CDS market, as measured by net outstanding, has been in decline since 2010. Figure 3 indicates that the same trend is seen in the gross notional outstanding as well.

\footnotetext{
${ }^{1}$ This number derives from taking the midpoint of the time-series average of the entire market $(\$ 30,772 \mathrm{bn})$ and the U.S. market $(\$ 17,138 \mathrm{bn})$. The logic is that the entire market is an upper bound, and the U.S. market size is a lower bound given I exclude any reference entity whose jurisdiction is ambiguous or undefined. These statistics are also consistent with those reported for international markets by the BIS in their end-of-June 2013 report: BIS 2013 CDS Report.
} 
Figure 3: Gross Notional Outstanding in CDS Markets

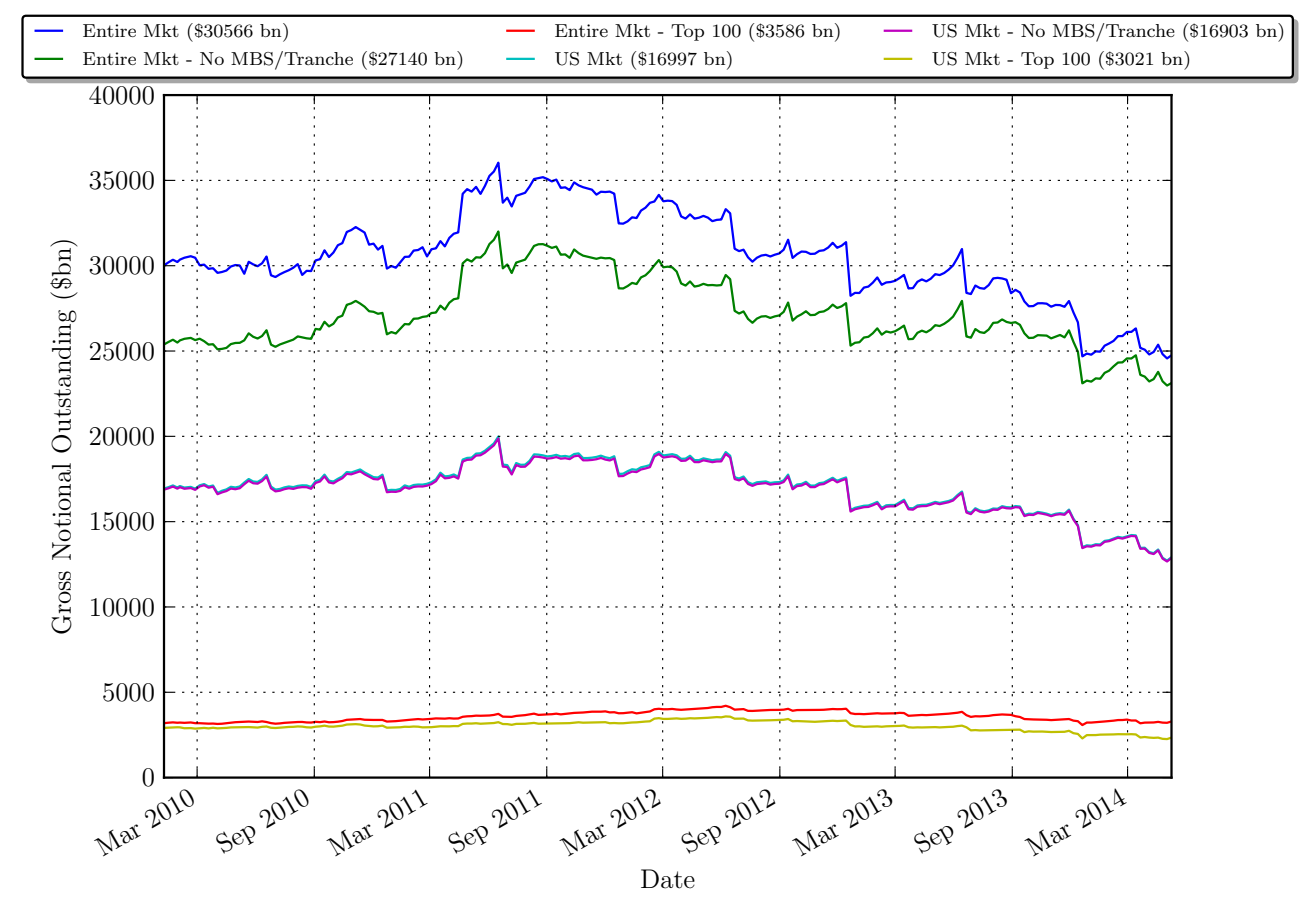

Notes: This figure plots the total gross outstanding in CDS markets. This statistic is plotted for: (i) using the entire dataset, (ii) using the entire data set, but excluding CDS written on MBS and tranches, (iii) the top 100 reference entities in the entire market. I then repeat the same set of filters for U.S. reference entities only, where a U.S. reference entity is refined according to the methodology in Data Appendix 1.4. In the legend, the numbers in parenthesis indicate time-series averages.

Finally, Figure 4 plots the ratio of net notional outstanding to gross notional outstanding for the entire CDS market. This ratio is informative because it gives a sense of how much risk is being transferred for each dollar of transactional volume. As is evident from the plot, the ratio of net notional to gross notional is, on average, roughly $7 \%$. For most of the sample period, the net-to-gross has been in decline. Using the entire dataset of swaps, the net-to-gross ratio has dropped from nearly $8.5 \%$ in January 2010 to roughly $6.3 \%$ in the summer of 2013. Since the summer of 2013, the trend has reversed slightly with the ratio at $6.7 \%$ as of March 2014. The decline in the net-to-gross ratio indicates that the net notional outstanding is falling faster than the gross notional outstanding. 
Figure 4: Net-to-Gross Notional Outstanding in CDS Markets

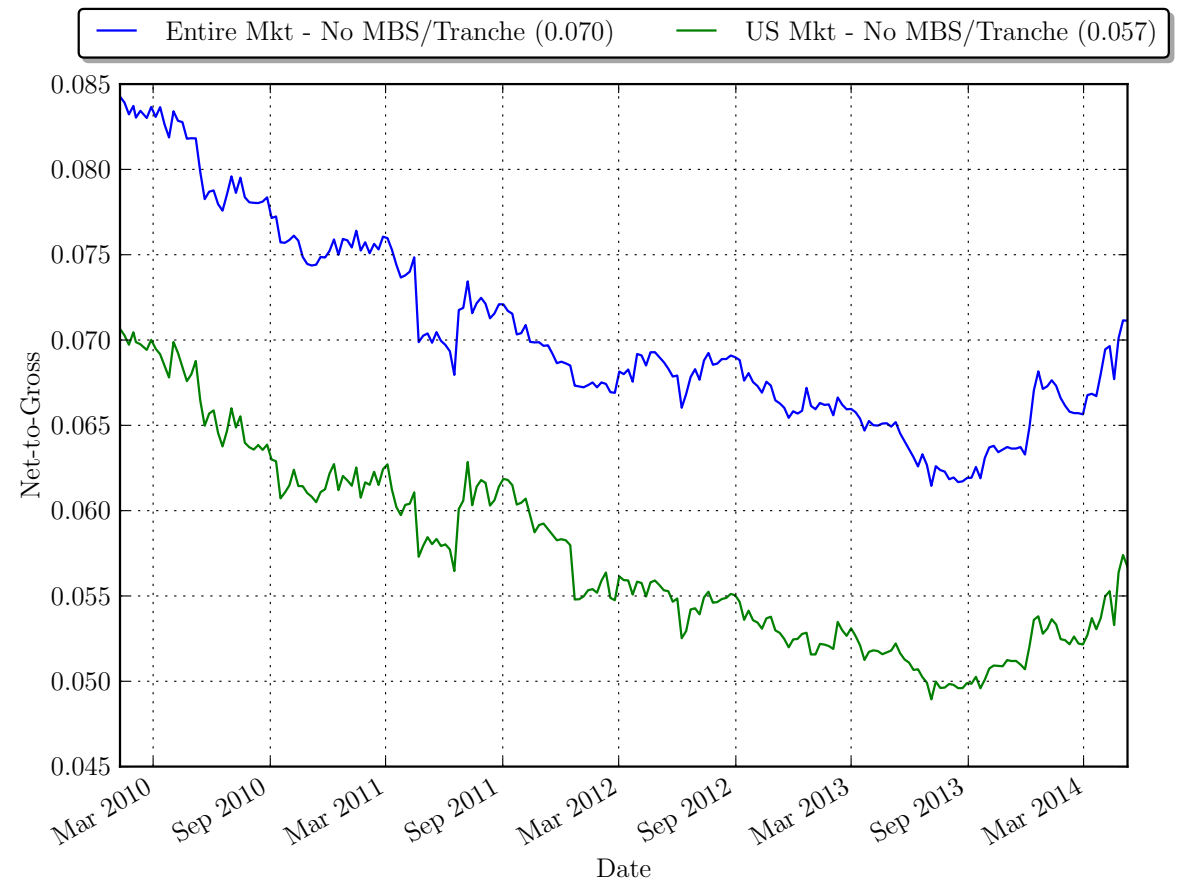

Notes: This figure plots the ratio of the total net notional to total gross outstanding in CDS markets. This statistic is plotted for: (i) the entire data set, but excluding CDS written on MBS and tranches, and (ii) U.S. reference entities, excluding CDS written on MBS and tranches reference entities. In the legend, the numbers in parenthesis indicate time-series averages.

\subsection{Credit Risk is Highly Concentrated within a Reference Entity}

\subsubsection{Concentration Ratios}

To quantify the concentration of buyers and sellers within a reference entity, I use concentration ratios, or the share of total net selling (buying) by the largest sellers (buyers). To fix ideas, I define the top five sellers of a reference entity $r$ on date $t$ as the set $T S(r, t)$. Similarly, I define the top five buyers as $T B(r, t)$. For each reference entity and date, seller and buyer concentration ratios are then given by:

$$
\begin{aligned}
C R_{S}(r, t) & =\sum_{c \in T S(r, t)} \frac{N S(c, r, t)}{N O(r, t)} \\
C R_{B}(r, t) & =\sum_{c \in T B(r, t)} \frac{|N S(c, r, t)|}{N O(r, t)}
\end{aligned}
$$

In the second line, I use the absolute value operator in the numerator because, by my definition, a net buyer overall has a negative net exposure.

Because there are thousands of reference entities traded, I aggregate $C R_{S}(r, t)$ or $C R_{B}(r, t)$ in two ways: (i) an equally weighted average of concentration across reference entities, and (ii) a size-weighted average of concentration across reference entities, where size is measured in the amount of net notional outstanding, 
Figure 5: How Much Risk is Bought/Sold by the Top 5 Counterparties?

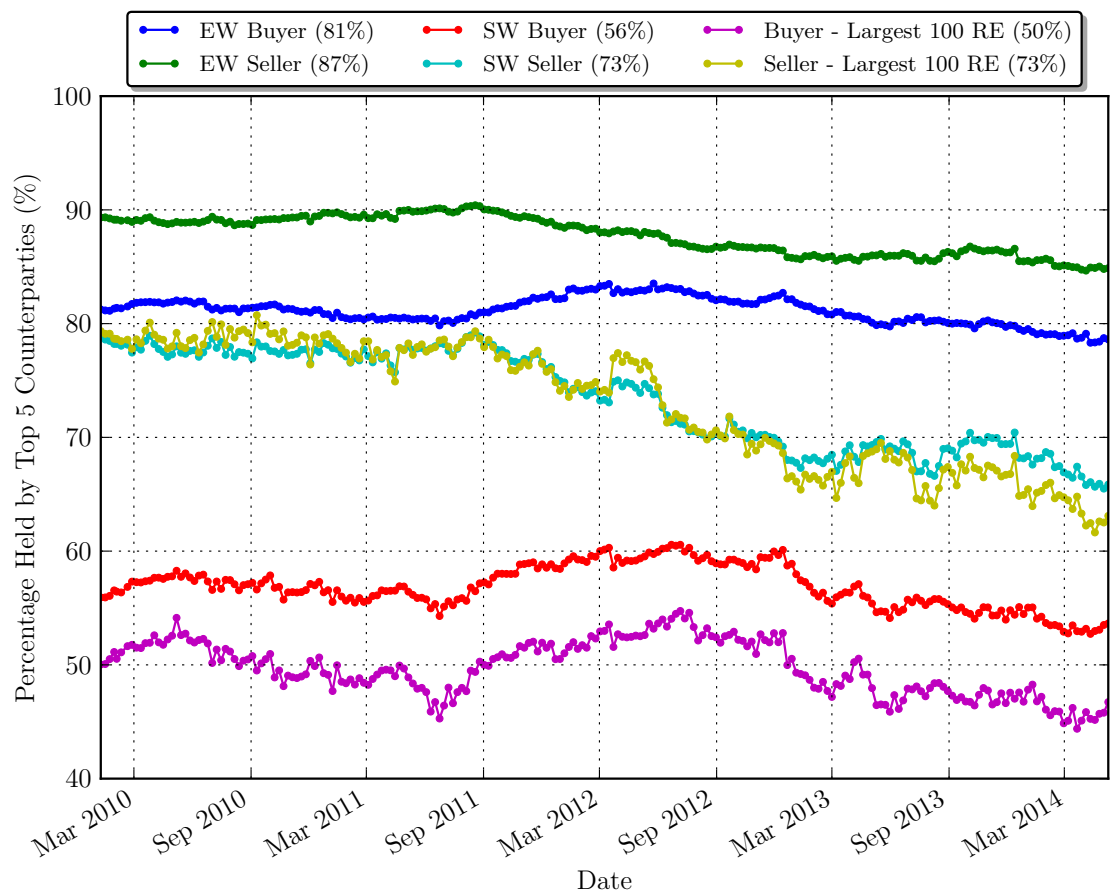

Notes: This figure plots the aggregate concentration of buyers and sellers in CDS markets. Seller (buyer) concentration is defined as the proportion of net selling (buying) by the top five largest sellers (buyers). This statistic is computed for each reference entity and date, and then aggregated by taking either an equal-weighted average or a size-weighted average. Finally, I compute the (equal-weighted) average for the largest 100 reference entities by net notional. In the legend, time-series averages are shown in parenthesis.

$N O(r, t)$. The reason for the latter is very small reference entities usually have only one or two sellers and buyers, which means the concentration indices for these reference entities are close to 100 percent. A sizeweighted average properly offsets this effect. Formally, I define size-weighted aggregate seller concentration index as follows:

$$
C R_{S}^{S W}(t)=\sum_{r \in \mathcal{R}_{t}} \frac{N O(r, t)}{N O(t)} \times C R_{S}(r, t)
$$

Size-weighted aggregate buyer concentration ratios are defined analogously. The equal-weighted counterparts are also self-explanatory. Figure 5 plots these various aggregate concentration ratio indices through time. In addition, this plot also displays the equal-weighted average buyer and seller concentration for the top 100 largest reference entities by net notional outstanding.

Figure 5 shows credit risk in CDS is highly concentrated for both buyers and sellers. Through the sample and for the average-sized reference entity, five sellers account for nearly 73 percent of the total amount of selling in CDS markets. Similarly, five buyers account for almost 57 percent of all buying. Sellers are also always more concentrated than buyers. This is true when considering reference entities equally, weighting them by size, or focusing on the 100 largest reference entities. Using the size-weighted indices as a benchmark, sellers are nearly 1.3 times as concentrated as buyers in CDS markets.

The concentration of sellers has nonetheless decreased over time. At the beginning of the sample, the top five sellers account for nearly 80 percent of selling within a reference entity. By the end of the sample, 
their share drops to 65 percent, still quite high. The reduction in seller concentration is robust to equally weighing reference entities, or considering only the largest 100. On the other hand, the concentration of buyers has remained relatively constant throughout the sample period. As of March 2014, the largest five buyers accounted for an average of 54 percent of all buying within a reference entity

The picture I have painted thus far is still incomplete because I have investigated only how concentrated buyers or sellers are within a particular reference entity. It is equally important to consider whether buyers or sellers are the same across reference entities, which I refer to as "commonality." .

\subsubsection{Herfindahl Analysis}

\section{A Static View}

After determining the amount of credit risk actually transferred via CDS, a natural question to ask is who ultimately bears the credit risk? While I cannot disclose the actual identities of the specific counterparties, I can summarize the degree of risk sharing in a series of plots. I wish to capture the degree of risk sharing for a given reference entity, so I define a reference entity $r$ 's buyer and seller Herfindahl as follows:

$$
\begin{aligned}
& H_{r t}^{B}=\sum_{c=1}^{C_{B}}\left(\frac{N B_{c r t}}{C R T_{r t}^{R}}\right)^{2} \\
& H_{r t}^{S}=\sum_{c=1}^{C_{S}}\left(\frac{N S_{c r t}}{C R T_{r t}^{R}}\right)^{2}
\end{aligned}
$$

where $N B_{c r t}=-N S_{c r t} 1_{N S_{c r t}<0}$, or in other words, is the net amount bought (in positive terms) by counterparty $c . C_{B}$ is the set of counterparties who are net buyers of protection on $r$, and $C_{S}$ is the set of counterparties who are net sellers of protection of $r . C R T_{r t}^{R}$ is the total amount of credit risk transferred for reference $r$ specifically, and is defined analogously to the overall amount of credit risk transferred via CDS as in Equation (1). ${ }^{2}$

$H_{r t}^{B}\left(H_{r t}^{S}\right)$ captures the extent that buyers (sellers) of $r$ are diversified in CDS markets. For example, if only one firm is the net buyer of all of CDS protection for $r$, then the buyer Herfindahl, $H_{r t}^{B}$, will be equal to one. Similarly, if one party bears all of the credit risk for $r$, then the seller Herfindahl, $H_{r t}^{S}$, will be one. For each reference entity, I plot the buyer versus seller Herfindahl as defined in Equation (4) in Figure $6 .^{3}$ In addition, I make the size of each point on the graph proportional to $C R T_{r t}$, since we might expect high buyer and seller concentrations for reference entities with small amounts of $C R T_{r t}$. The top panel of the figure includes credit default swaps written on mortgage backed securities. The bottom panel repeats the same exercise, but excludes CDS written on MBS for reasons discussed in the Data Appendix Section 2.3.2.

A similar set of conclusions can be drawn from both panels of Figure 6, so I will focus on the bottom

\footnotetext{
${ }^{2}$ Formally, this means:

$$
\begin{aligned}
C R T_{r t}^{R} & =\frac{1}{2} \sum_{c=1}^{C}\left|N S_{c r t}\right| \\
C R T_{t}^{R} & =\sum_{r=1}^{R} C R T_{r t}^{R}
\end{aligned}
$$
}

${ }^{3}$ For computational reasons, I define a reference entity by its RedID only. 
Figure 6: Buyer and Seller Herfindahls for 11/26/2013
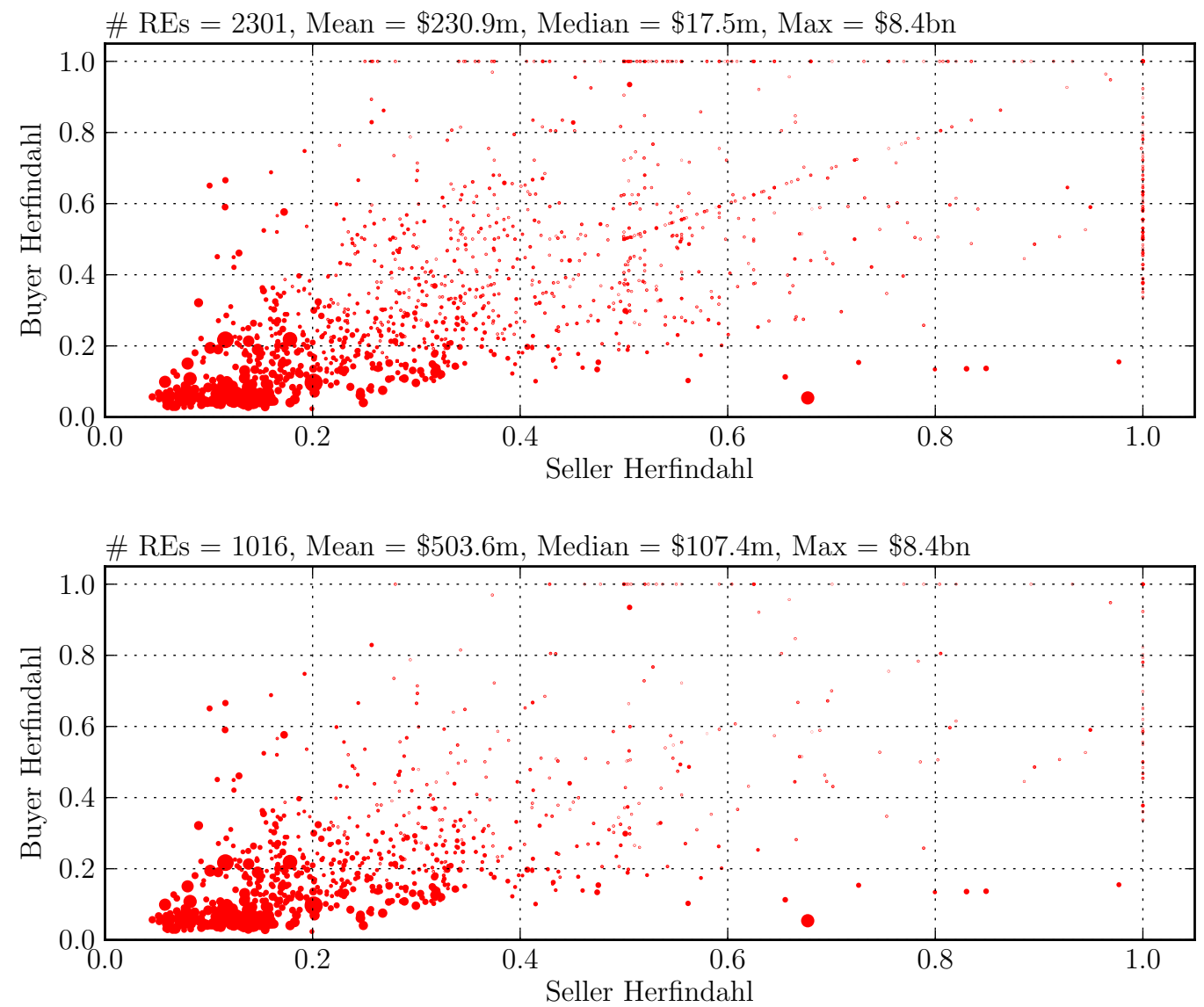

Notes: The figure above plots, for each reference entity $r$, the buyer against the seller Herfindahls as defined in Equation (4). A reference entity, $r$, is defined by its RedID. In the top panel, I plot all credit default swaps , including those written on mortgage backed securities. The bottom panel repeats the same exercise, but excludes CDS written on MBS for reasons discussed in the Data Appendix Section 2.3.2.. The size of each point is proportional to the amount of credit risk transferred $\left(C R T_{r t}\right)$ for each reference entity. Thus, bigger dots represent reference entities with large amounts of credit risk being transferred via CDS. Along the top of the figure are summary statistics for this particular date $(11 / 26 / 2013)$. \#REs is the total number of reference entities in the sample for this date. The remaining statistics describe the cross-section of $C R T_{r t}$. 
panel. As the statistics along the top of the lower panel show, the average amount of credit risk transferred for a reference entity is about $\$ 500$ million. Still, there are also firms with large amount of outstanding credit risk transferred, with the maximum amount being $\$ 8.4$ billion. As far as concentration, there are certainly firms whose credit risk is bought or sold by one person, and one person only. The outer border in the plot where at least one of the Herfindahl measures is equal to one shows these cases, but it is also evident that most of these firms are relatively small in terms of credit risk transferred. The more interesting firms are those that are large in size and far away from the origin as these correspond to large reference entities with concentrated buyers and sellers - there are quite a few of these firms as well. One way to quantify the relationship between the size of the reference entity and its buyer (seller) concentration is to compare the economy wide size-weighted average (buyer) Herfindahl to its equal-weighted counterpart:

$$
\begin{aligned}
\bar{H}_{E W, t}^{p} & =\frac{1}{R_{t}} \sum_{r=1}^{R_{t}} H_{r t}^{p} \\
\bar{H}_{V W, t}^{p} & =\sum_{r=1}^{R_{t}} \omega_{r t} H_{r t}^{p}
\end{aligned}
$$

where $\omega_{r t}=C R T_{r t}^{R} / \sum_{r} C R T_{r t}^{R}$ and $p \in\{B, S\}$. Starting with buyers, the equal-weighted and size-weighted Herfindahl for this particular date are 0.60 and 0.12 , respectively. Many esoteric reference entities unsurprisingly have only one buyer and one seller; still, clearly, these reference entities are not large in size given that the size-weighted buyer Herfindahl is 0.12. On the seller side, the equal-weighted and size-weighted Herfindahl are 0.6 and 0.17 , respectively. Like with buyers, this large difference is driven by thinly traded reference entities. Focusing on the size-weighted buyer and seller Herfindahl, we can see that sellers are more concentrated than buyers on this particular date. As we will see shortly, this is a persistent pattern throughout the sample.

\section{Concentration Dynamics}

The preceding analysis applies for only $11 / 26 / 2013$, so Figure 7 also plots the time series of the various economy-wide Herfindahl indicies defined in Equation (5).

As documented in Section 2 of the main text, larger reference entities (as measured by net outstanding notional) account for an enormous proportion of the entire market. As such, I will focus on the dynamics size-weighted Herfindahl indices for the remainder of the analysis. The first takeaway from Figure 7 is that the aggregate concentration of credit risk bearers (i.e. net sellers) and hedgers (i.e. net buyers) is stable through time. There is a slight decreasing trend in the concentration of sellers towards the end of the sample, but for the most part there are little dynamics in credit risk concentration. The second takeaway is that sellers are more concentrated than buyers. Averaged over the entire sample, the size-weighted seller Herfindahl is $66 \%$ larger than the analogous buyer Herfindahl.

The last set of time-series in Figure 7 corresponds to the buyer and seller Herfindahls for the top 100 reference entities in terms of outstanding net credit risk. Buyers of the top 100 reference entities are slightly less concentrated than economy wide concentration measure. The concentration of sellers of the top 100 reference entities highly resembles the aggregate seller concentration index, but declines slightly below the aggregate seller Herfindahl towards the end of the sample. 
Figure 7: Time-Series of CDS Concentration

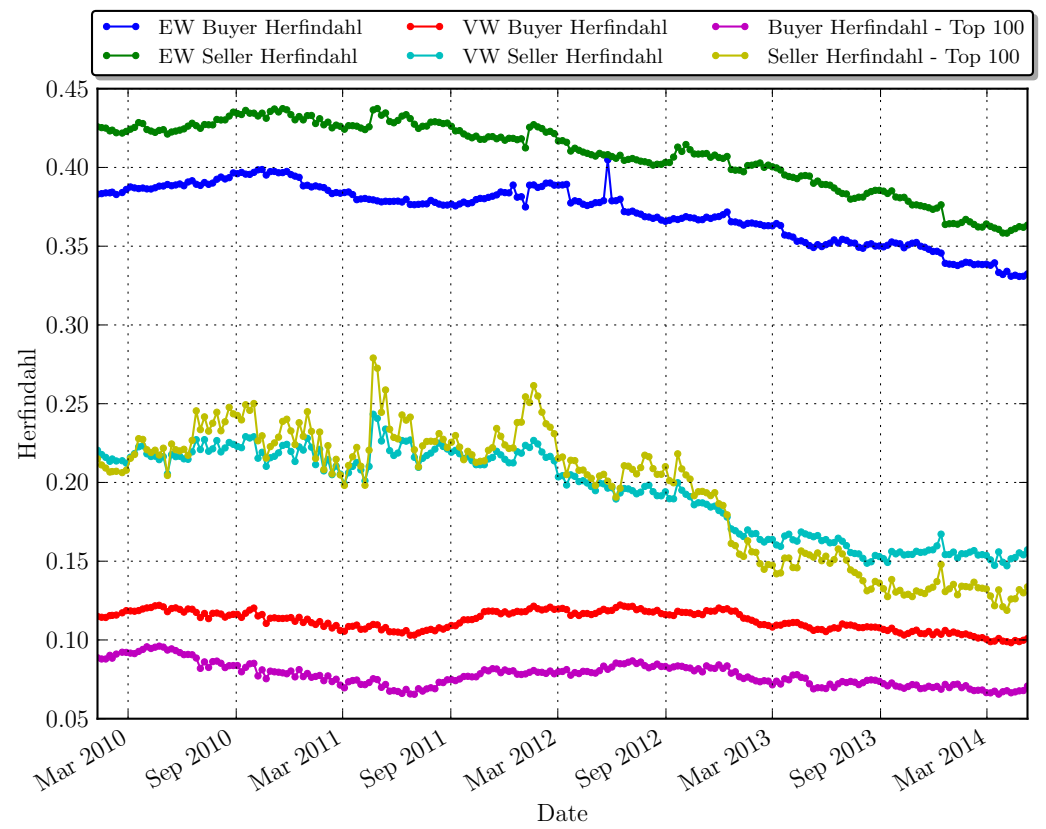

Notes: This figure plots various aggregate Herfindahl indices for credit risk sharing in the U.S. CDS market. The series corresponding to the top 100 indicates the firms with the most amount of net credit risk outstanding. "EW" corresponds to equal-weighted indices, and "VW" corresponds to size-weighted indices. 
What Do We Expect Concentration To Be? The average seller Herfindahl over the sample is 0.21, whereas the average buyer Herfindahl is 0.13 . What is a reasonable benchmark for the buyer and seller Herfindahl's in this market? A rough back of envelope calculation is instructive for this purpose. For simplicity, consider a single reference entity, $r$. Denote the number of natural sellers in the market at any point in time as $N_{S}$. The number of natural buyers in the market at any point in time is denoted by $N_{B}$. As an extreme example, I further assume that the distribution of buying and selling is equally distributed across participants. In this case, it is straightforward to show that the buyer and seller Herfindahl for reference entity $r$ should be $1 / N_{B}$ and $1 / N_{S}$, respectively. In Section 1.4 , I show that there are, on average, roughly two hundred ninety one net sellers of protection in the market, and six hundred ninety three net buyers of protection. ${ }^{4}$ Thus, $N_{S}=291$ and $N_{B}=693$; in the equally distributed benchmark, the buyer and seller Herfindahl for a given reference entity should then be 0.0034 and 0.0014 , respectively. Clearly, the concentration of buyers and sellers far exceeds this equally distributed benchmark.

Credit is well-known to be a highly specialized investment class, and we might therefore expect a small subset of market participants to focus on a particular reference entity. To extend the back of envelope calculation, I posit that a set fraction $\alpha_{S}$ of all natural sellers is active for reference entity $r$. Analogously for buyers, this fraction is $\alpha_{B}$. It is easy to see that in order to match the observed aggregate seller Herfindahl, then $\alpha_{S} \approx 0.016$. In other words, $1.6 \%$ of all available sellers must absorb the credit risk for reference entity $r$ in order to match the aggregate data. Even using the minimum seller Herfindahl for the top 100 reference entities yields an $\alpha_{S} \approx 2.9 \%$. Similarly, $\alpha_{B} \approx 2 \%$ in order to match the data. ${ }^{5}$ Obviously a more formal model of credit risk sharing is needed to carefully interpret the aggregated buyer and seller Herfindahls in the data, but these preliminary computations certainly suggest an extremely high degree of credit risk concentration for both buyers and sellers in CDS markets.

\subsection{Credit Risk Is Highly Common Across Counterparties}

I now propose simple measures of commonality of buyer ownership and seller ownership. For instance, two reference entities have high buyer commonality if there is a large overlap of net buyers of their CDS. First, define the common buyer measure at time $t$, denoted by $C B_{i j t}$, as:

$$
C B(i, j, t):=-\frac{\sum_{c=1}^{O_{B}}(N S(c, i, t)+N S(c, j, t))}{N O(i, t)+N O(j, t)}
$$

where $O_{B}$ is the number of parties who are net buyers of both $i$ and $j$ at time $t$. The negative sign in the definition comes from, again, the fact that I define net buyers as negative net sellers. The common seller measure, $C B(i, j, t)$, is similarly defined but uses the set of net sellers who are common to both reference entities.

Both buyer and seller overlap measures are bounded between zero and one. Naturally, if there is no

\footnotetext{
${ }^{4}$ By net seller of protection I mean the total exposure across all counterparties and all reference entities. As already discussed, this is not the perfect measure of a true net bearer of credit risk, but for the current purposes it is sufficient.

${ }^{5}$ In the Online Appendix, I provide some more calibrations along this line of thinking, but extend the treatment across all reference entities. Specifically, I consider a limited participation equal sharing benchmark. For the top 100 reference entities, it is natural to assume that $\alpha_{S}$ and $\alpha_{B}$ are constant. A parallel calibration yields similar results.
} 
Table 3: Cross-Sectional Distribution of CDS Overlap

\begin{tabular}{|c|c|c|c|c|c|c|c|c|c|c|c|}
\hline & \multicolumn{5}{|c|}{ Buyer Overlap } & \multicolumn{5}{|c|}{ Seller Overlap } \\
\hline & & \multirow[b]{2}{*}{ Mean } & \multicolumn{4}{|c|}{ Percentile } & \multirow[b]{2}{*}{ Mean } & \multicolumn{4}{|c|}{ Percentile } \\
\hline Year & Avg. \# Pairs & & 25 & 50 & 75 & 95 & & 25 & 50 & 75 & 95 \\
\hline ALL & 651,845 & 0.223 & 0.010 & 0.169 & 0.371 & 0.667 & 0.269 & 0.008 & 0.201 & 0.467 & 0.774 \\
\hline 2010 & 777,113 & 0.201 & 0 & 0.137 & 0.339 & 0.623 & 0.252 & 0 & 0.165 & 0.448 & 0.764 \\
\hline 2011 & 693,022 & 0.219 & 0 & 0.159 & 0.363 & 0.663 & 0.270 & 0 & 0.200 & 0.475 & 0.779 \\
\hline 2012 & 620,263 & 0.237 & 0.009 & 0.187 & 0.391 & 0.685 & 0.278 & 0.008 & 0.216 & 0.478 & 0.775 \\
\hline 2013 & 526,439 & 0.251 & 0.027 & 0.191 & 0.387 & 0.694 & 0.278 & 0.023 & 0.220 & 0.466 & 0.777 \\
\hline 2014 & 487,907 & 0.145 & 0.044 & 0.208 & 0.396 & 0.697 & 0.279 & 0.027 & 0.201 & 0.459 & 0.775 \\
\hline
\end{tabular}

Notes: This table presents summary statistics for the distribution of buyer and seller overlap measures. The pairwise seller (buyer) commonality between reference entities $i$ and $j$ is the proportion net sellers (buyers) who are common to $i$ and $j$. Observations are grouped together by year and exclude CDS written on Mortgage Backed Securities (see Data Appendix 1.4.2).

overlap between two reference entities, the corresponding overlap measure will be zero. Similarly, if one counterparty is the only buyer (seller) of protection in both reference entities, then the buyer (seller) overlap measure will be one.

\section{Empirical Results}

Table 3 summarizes my commonality statistics across reference entities and time. Over the whole sample, the average pair of reference entities has 22 percent of their buyers in common and 27 percent of their sellers in common. Anton and Polk (2013) compute a similar set of computations for mutual fund ownership in equities. Their sample ranges from 1980 to 2010, and they find the maximum average overlap for stock ownership to be 1.6 percent. Clearly, credit risk in CDS markets has a much more common ownership base compared to equities.

Some reference entity pairs have a great deal of overlap in both their sellers and buyers of protection. The top 5 percent percentile of reference entities pairs have 67 percent of their buyers in common, and 77 percent of their sellers in common. The reference entities with the most common buyers and sellers are also the largest. To highlight this fact, Figure 8 plots the equal-weighted average overlap measure over all pairs for the top 100 reference entities.

For the largest reference entities, an average of 80 percent of the credit risk in CDS is borne by a common set of counterparties. Is this problematic? It seems reasonable to think a large number of counterparties might equallysell protection on many of the largest reference entities. ${ }^{6}$ This would give rise to a large average pairwise seller overlap in the largest reference entities, but also a small seller concentration. As we saw in Figure 5, this is not the case. In order for the seller overlap measure in Figure 8 to simultaneously match the concentration analysis in Section 1.2, it must be that only a few counterparties are responsible for credit risk transfer in the U.S. credit default swap market. The extremely small number of net sellers and net buyers overall is further confirmed in the Online Appendix Section 1.4, when I simultaneously study how and where credit risk flows through the CDS network.

\footnotetext{
${ }^{6}$ In the extreme, consider the simplest CAPM environment from equities. In this case, everyone holds the market portfolio. This would indicate a very large commonality across equities, but also a very small ownership Herfindahl within any given name.
} 
Figure 8: Buyer and Seller Commonality for CDS Markets

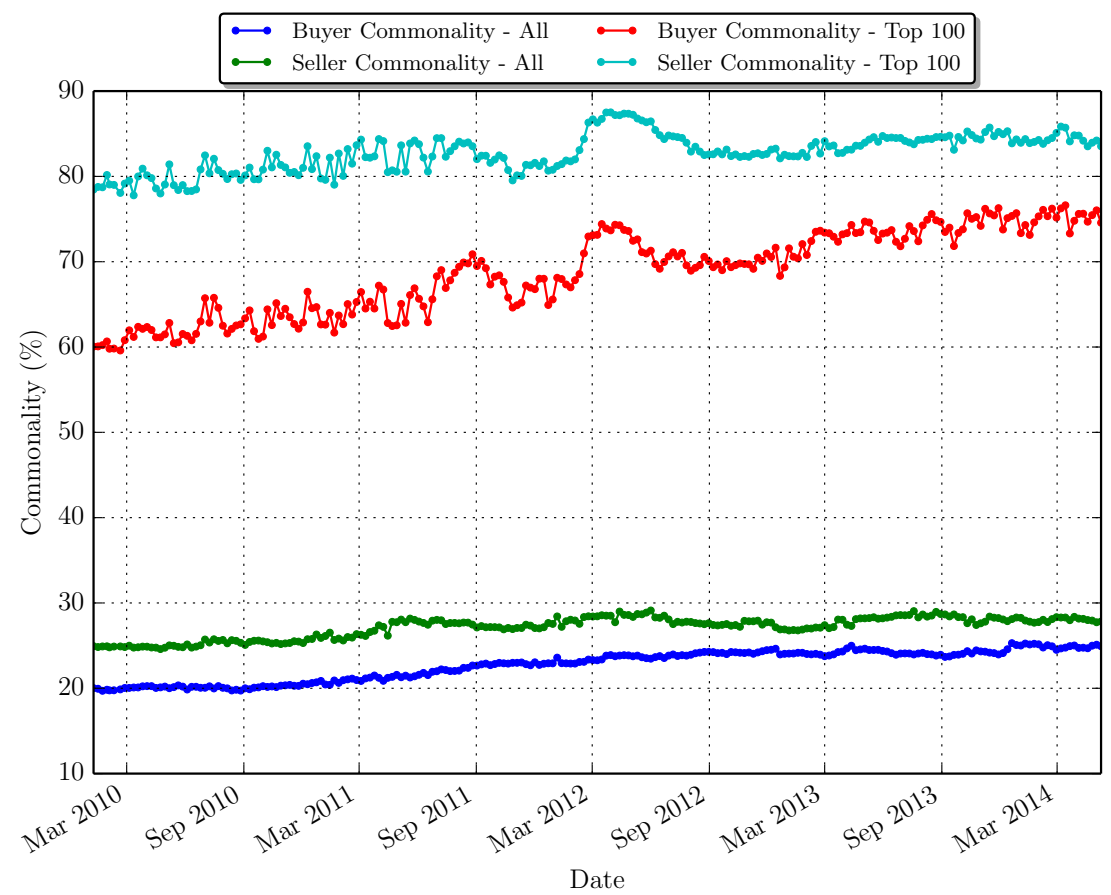

Notes: This figure plots the average pairwise buyer and seller commonality measures through time. The pairwise seller (buyer) commonality between reference entities $i$ and $j$ is the proportion net sellers (buyers) who are common to $i$ and $j$. The series corresponding to the top 100 refers to the average buyer and seller commonality across all pairwise combinations of the 100 reference entities with largest net notional outstanding.

\subsection{Who Bears Credit Risk and Who Buys Protection?}

\subsubsection{Overall Net Sellers and Buyers}

Given the sheer size of the CDS market, it is important and interesting to know who are the actors who bear credit risk (i.e. sell protection) and offload credit risk (i.e. buy protection). I categorize, at a high level, the number of buyers and sellers in the CDS market at any point in time. In the interest of a simple approximation, I compute the net exposure of a counterparty $c$ by summing exposures over all reference entities and all of $c$ 's counterparties. Figure 9 then plots the number of net sellers and the number of net buyers through time.

Net overall sellers of CDS protection are more scarce than net buyer of CDS, as the average number of net buyers is over twice the average number of net sellers. These results are consistent with the concentration analysis in the main text. Since these computations are netted over all reference entities and counterparties, I now turn to categorizing net sellers and net buyers for each reference entity.

\subsubsection{Seller and Buyers by Reference Entity}

In order to get a sense of who/how sellers and buyers are distributed across each reference entity, I first assign (by hand) every counterparty in my dataset to one of the types listed in Table 4 . 
Figure 9: Number of Net Sellers and Net Buyers

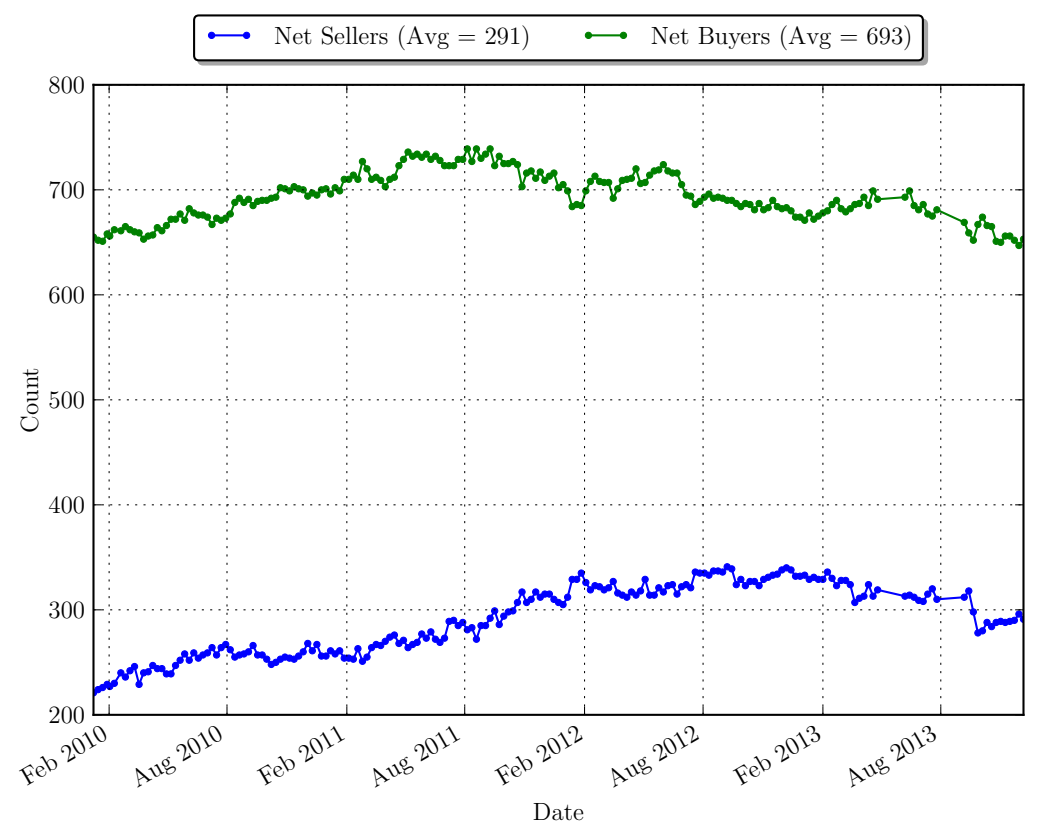

Notes: This figure plots the number of net sellers and net buyers in the CDS network through time. A net seller (buyer) is a market participant whose total net exposure across all reference entities and counterparties is positive (negative). 
Figure 10: Proportion of Buyers and Sellers, by Type, for each Reference Entity
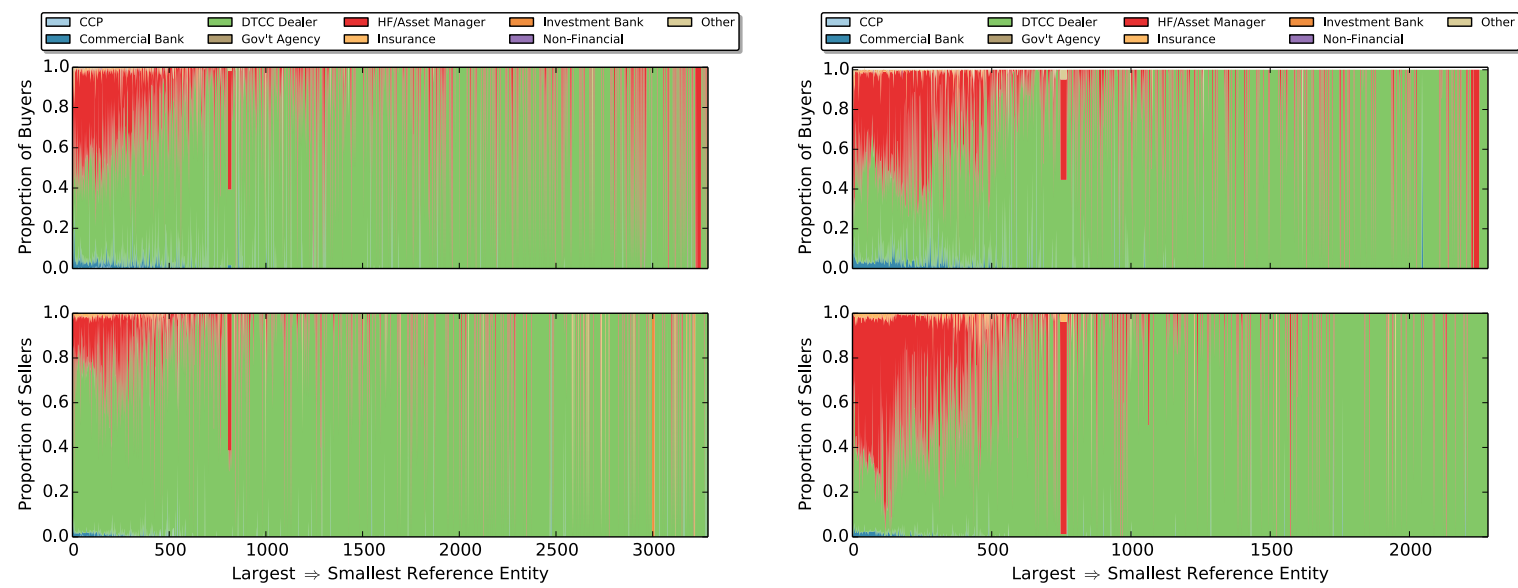

Notes: The top panel of each sub-figure plots the proportion of buyers, by each type, for each reference entity. Reference entities are indexed along the x-axis, and move from largest to smallest in terms of net credit risk outstanding. The bottom panel repeats the same exercise, but for net sellers. The left sub-figure date corresponds to $5 / 13 / 2011$, and the right sub-figure corresponds to $12 / 06 / 2013$.

Table 4: Counterparty Types

\begin{tabular}{|c|c|}
\hline Types & Types \\
\hline CCP (Central Counterparty) & Insurance \\
\hline Commercial Bank & Investment Bank \\
\hline DTCC Dealer & Non-Financial \\
\hline Government Agency & Other \\
\hline Hedge Fund or Asset Manager & \\
\hline
\end{tabular}

Notes: This tables describes the types of counterparties found in the data.

Denote the total set of types in Table 4 as $\mathcal{Y}$, and a single element in this set as $y$. Next, for a particular reference entity $r$, I denote the proportion bought by type $y$ at time $t$ as $P_{B}(y, r, t)$. Similarly, the proportion sold by type $y$ at time $t$ on reference entity $r$ is given by $P_{S}(y, r, t)$.

Figure 10 plots the results of this computation across all reference entities. The top panel of the figure represents the buyer breakdown, and the bottom panel represents the seller breakdown. Reference entities are indexed along the x-axis, with the largest reference entity on the left.

The sub-figure on the left portion of Figure 10 depicts the U.S. CDS market on 5/13/2011. At this point in time, the two major types of buyers were hedge funds/asset managers and dealers. ${ }^{7}$ As the top panel of the left sub-figure demonstrates, this pattern is particularly true for the largest reference entities. The bottom panel of the left sub-figure shows that, on $5 / 13 / 2011$, dealers were the predominant seller of protection for the almost all reference entities. For some of the largest reference entities, the share of dealers net selling protection ranges from reaches almost $80 \%$.

The sub-figure on the right portion of Figure 10 shows the same breakdown as of $12 / 06 / 2013$. While

${ }^{7}$ I denote them as DTCC dealers since these are the set of dealers as classified by the DTCC. A partial list can be found on DTCC's official website. 
the composition of buyers looks about the same (the top panel of the right sub-figure), the composition of sellers changed quite a bit from 5/6/2013 to 12/6/2013. Among the largest reference entities, hedge funds/asset managers now are the predominant sellers of protection $(\sim 60 \%)$. Still, dealers remain important bearers of credit risk, both in the largest reference entities, but more specifically in the smaller reference entities. Indeed, there are still some large reference entities where dealers make represent over $30 \%$ of the net protection sellers; for smaller reference entities, dealers remain the majority sellers of protection.

Taken together, the snapshots provided in Figure 10 suggest that dealers and hedge funds/asset managers sell protection to other dealers and hedge funds/asset managers. This is an important fact to realize since the total net position across, say, all dealers will mask the fact that there is a substantial amount of risk being transferred within the dealer network. Moreover, it is clear from Figure 10 that the role of dealers in CDS markets is more than just market making; some dealers act as ultimate bearers of credit risk for a large number of firms, and other dealers act as ultimate hedgers of credit risk.

\subsubsection{Creating Aggregate Indices}

The aggregate amount bought by a particular type is then the weighted-average of $P_{B}(y, r, t)$ across reference entities, where the weight is proportional to the size of the reference entity. Formally, this means:

$$
\begin{aligned}
& \bar{P}_{B}(y, t)=\sum_{r=1}^{R_{t}} \omega_{r t} P_{B}(y, r, t) \\
& \bar{P}_{S}(y, t)=\sum_{r=1}^{R_{t}} \omega_{r t} P_{S}(y, r, t)
\end{aligned}
$$

where $\omega_{r t}=N O(r, t) / \sum_{r} N O(r, t)$. These statistics are the basis of Figure 4 in the main text.

\subsection{How Do Counterparties Meet in the CDS Network?}

\subsubsection{A Static View}

Sellers of CDS protection absorb the credit risk of the underlying reference obligation from buyers. In this way, the credit risk flows from the ultimate buyers of CDS to the ultimate sellers of CDS. Because OTC markets are heavily intermediated, the flow of credit risk must pass through broker-dealers before reaching its ultimate destination. The purpose of this subsection is therefore to use my proprietary data to trace out how risk actually flows through CDS markets. Figure 11 plots what I call the counterparty network in CDS. Nodes in this network are counterparties. Two nodes are connected if there is existing position outstanding between the two counterparties. Hence, edges in this network are undirected and simply denote a business relationship between two nodes. A weighted and undirected network is the appropriate representation in this context, given that I am interested in how risk flows rather than where risk flows. ${ }^{8}$ The size of a node is proportional to the number of that node's connections; in network jargon, nodes are sized in proportion to their degree.

The dealer centric nature of CDS markets is easily seen in Figure 11. Dealers correspond to the handful of very large red nodes, which indicates these nodes have many connections. The remaining nodes in this

\footnotetext{
${ }^{8}$ Conversely, I consider where risk flows using a directed and weighted network in Section 1.6.
} 
Figure 11: Counterparty Connections in the CDS Network

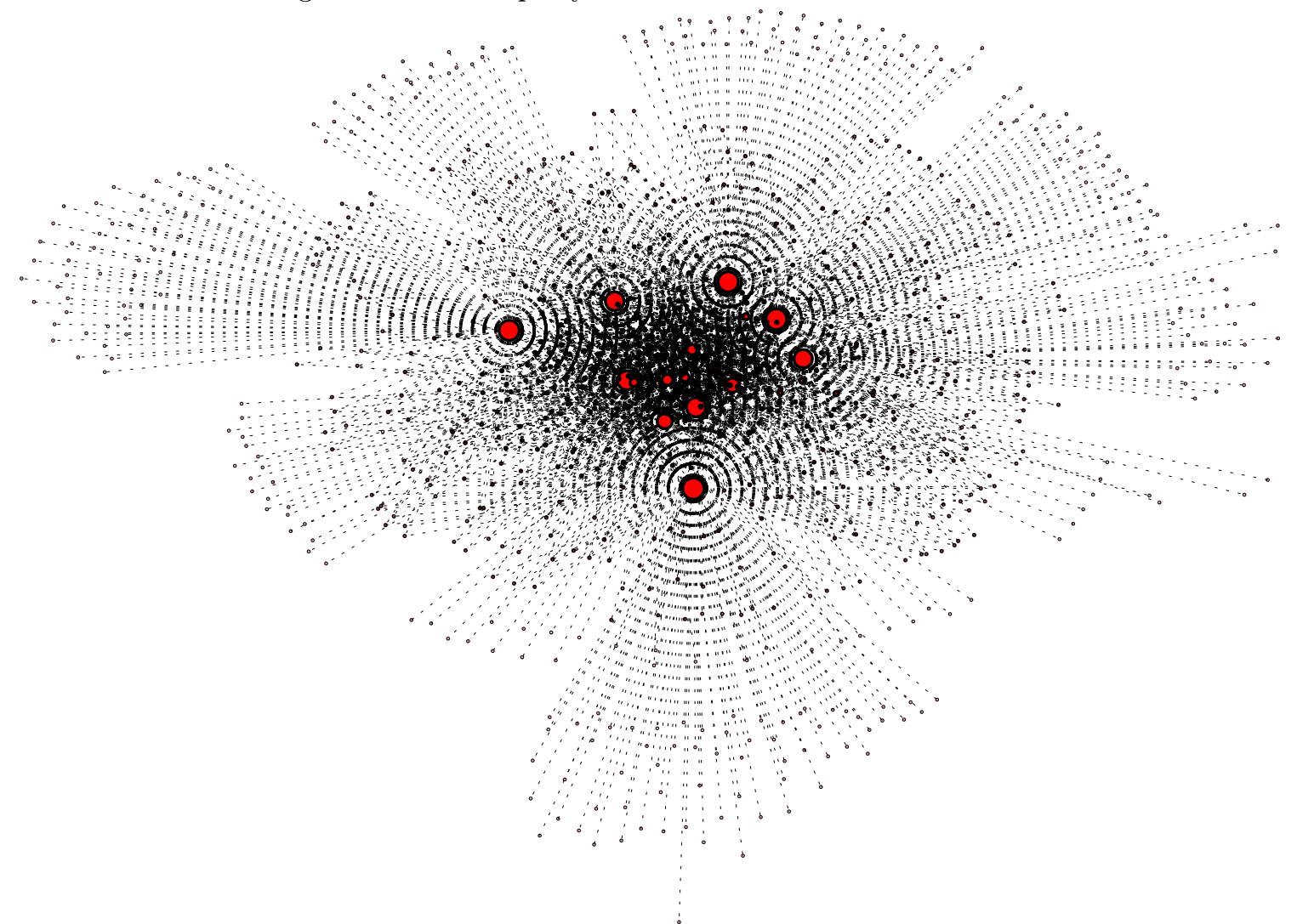

Notes: This figure plots the network of counterparty connections in CDS markets using data on $7 / 26 / 2013$. Two nodes are connected if there is any net exposure between them. The size of each node is proportional to the number of connections that node has, so that larger nodes have more connections. 
network are end-users such as hedge funds, mutual funds, etc. Another salient feature of the CDS network is that dealers connect otherwise disjoint subnetworks of end-users. To see why, notice that each of the large red nodes seems to have a set of end-users with only they connect with. ${ }^{9}$ Thus, in order for credit risk to flow from one subnetwork of end-users to a disjoint subnetwork of end-users, the risk must pass through at least the two dealers who connect with each different subnetwork. The willingness of dealers to intermediate is seemingly an important component for risk to flow effectively through the system.

To quantify more concretely the structure of the CDS network in Figure 11, I present a statistical summary of the degree distribution over time in Table 5. In addition, I recompute the degree distribution statistics for subsamples of dealers and non-dealers only. The median non-dealer faces only three counterparties. Non-dealer to non-dealer trades are extremely rare, so in essence, the median non-dealer faces three other dealers. On the other hand, the median dealer faces one hundred forty five different counterparties. Still, not all dealers are like, as evidenced by the fact that the $75 \%$ percentile dealer faces nearly four hundred counterparties.

Table 5: Degree Distribution of Counterparty CDS Network: Summary

\begin{tabular}{|c|c|c|c|}
\hline Degree & All Parties & Dealers & Non-Dealers \\
\hline Min & 1 & 1 & 1 \\
\hline Lower Quartile & 1 & 27.6 & 1 \\
\hline Median & 3 & 145.4 & 3 \\
\hline Mean & 9.3 & 210.8 & 4.5 \\
\hline Upper Quartile & 7.3 & 403.5 & 7 \\
\hline Max & 492 & 492 & 15 \\
\hline
\end{tabular}

Notes: This table summarizes degree distribution of the network in Figure 11, but also considers sub samples of counterparties based on whether they are a dealer or not. The lower quartile, median, mean, and upper quartile are averaged over time. The min and the max are the minimum and maximum over time, respectively.

While end-users must rely heavily on dealers to transfer risk through the counterparty network, the size of the network itself is not all that large. One measure of network size is the so-called diameter, which measures the maximum number of steps between any two counterparties. In this case, the diameter is four, owing to the fact that the interdealer network is itself highly connected. Because all of the dealers are connected to each other, their respective subnetworks are not "far" apart.

Let me now quantitatively highlight the role of dealers in connecting disjoint end-user networks by computing two measures of centrality for each node in the counterparty CDS network: (i) betweenness centrality and (ii) eigenvector centrality. ${ }^{10}$ Loosely speaking, a node $n$ will have a high betweenness centrality if a large fraction of the shortest paths between other node pairs passes through $n$. A node has a high eigenvector centrality if it has many connections, but also if it is connected to other nodes that have many connections. Figure 12 collects these two metrics for all nodes in the network, and for only the subset of dealers.

Starting with betweenness centrality, most nodes have a measure of zero. These correspond to end-user

\footnotetext{
${ }^{9}$ Why might this network structure form endogenously? One explanation is that setting up a CDS trading account is costly. For instance, one must set up an ISDA account and set margining agreements. Farboodi (2014) and Atkeson, Eisfeldt, and Weill (2013) develop theoretical models of endogenous network formation between financial institutions. While interesting in itself, endogenous network formation is not within the scope of this paper.

${ }^{10} \mathrm{~A}$ complete definition of all of the network statistics in the paper can be found Appendix 3.
} 
Figure 12: Betweenness Centrality and Eigenvector Centrality in CDS Network
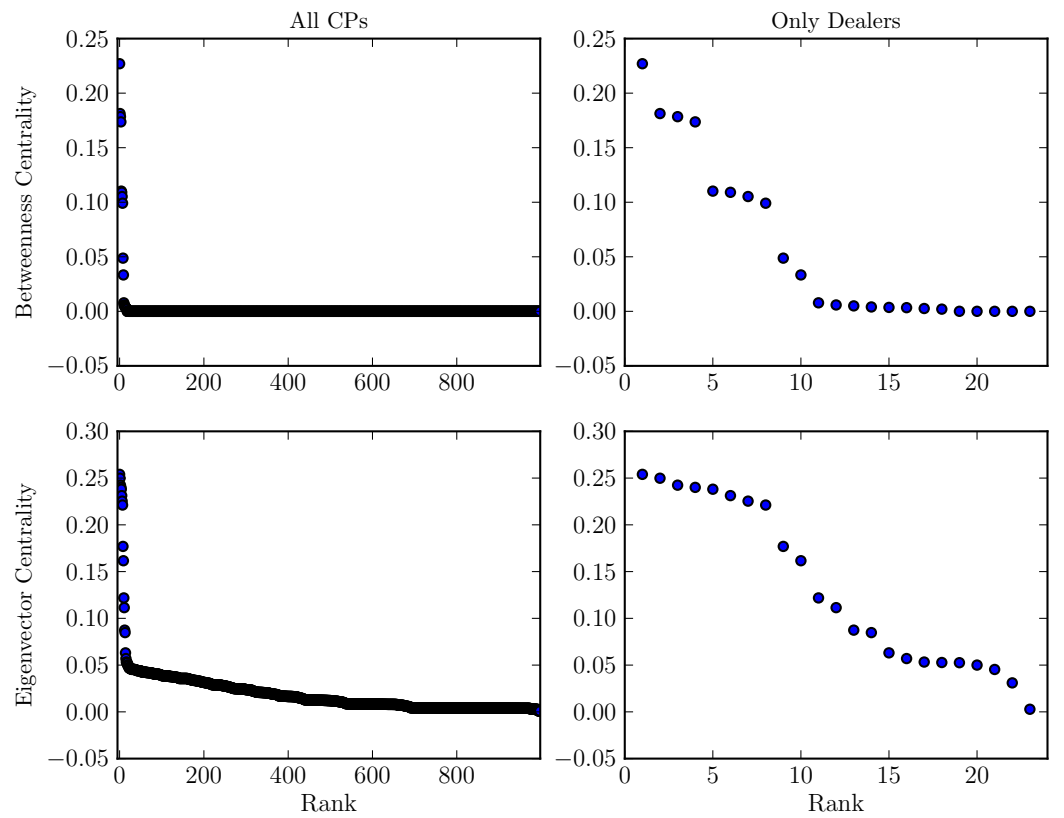

Notes: This figure provides a summary of centrality statistics for the network of CDS counterparties on $7 / 26 / 2013$.

nodes who do not participate in the intermediation chain. Within the dealer network, there are clearly a set of core intermediaries, as seen in the top left panel of Figure 12. Four broker-dealers have betweenness centrality measures of over 0.15 , with one dealer having a betweenness centrality of just under 0.25 . In other words, one dealer is along $25 \%$ of the shortest chains connecting end-users. There is also a second tier of broker dealers having betweenness centrality measures of roughly 0.10 . The eigenvector centrality measures in the bottom panels echo much of the results from betweenness centrality. In total there appear to be eight dealers who are responsible for a large majority of the risk flows in CDS markets, with a subset of four dealers who are particularly core to the network. These two centrality measures also emphasize the "tree" like network that stands out in Figure 11.

\subsubsection{Counterparty Network Dynamics}

The analysis to this point has been static, but it is equally important to understand how or if the structure of the network evolves over time. Panel A of Figure 13 begins by plotting the degree distribution through time. As is clear from the figure, the degree distribution is quite stable through time, indicating that the number of potential counterparties that each player in the market faces does not move much. ${ }^{11}$ The bottom panel of Figure 13 plots the distribution of eigenvector centrality through time. ${ }^{12}$ Recall that eigenvector

\footnotetext{
${ }^{11}$ In this context, it is important to understand what a stable degree distribution means. The counterparty network I am currently describing speaks nothing of risk flows. Instead, it is designed to capture "CDS connections".

12 I choose to focus on eigenvector centrality over betweenness centrality, since betweenness centrality for most counterparties (i.e. all end-users) is zero. I will return to betweenness centrality in the context of the dealer network shortly. In addition, in unreported results I confirm that the diameter of the counterparty network is either three or four for the entire sample.
} 
Figure 13: Counterparty Network Distribution Through Time
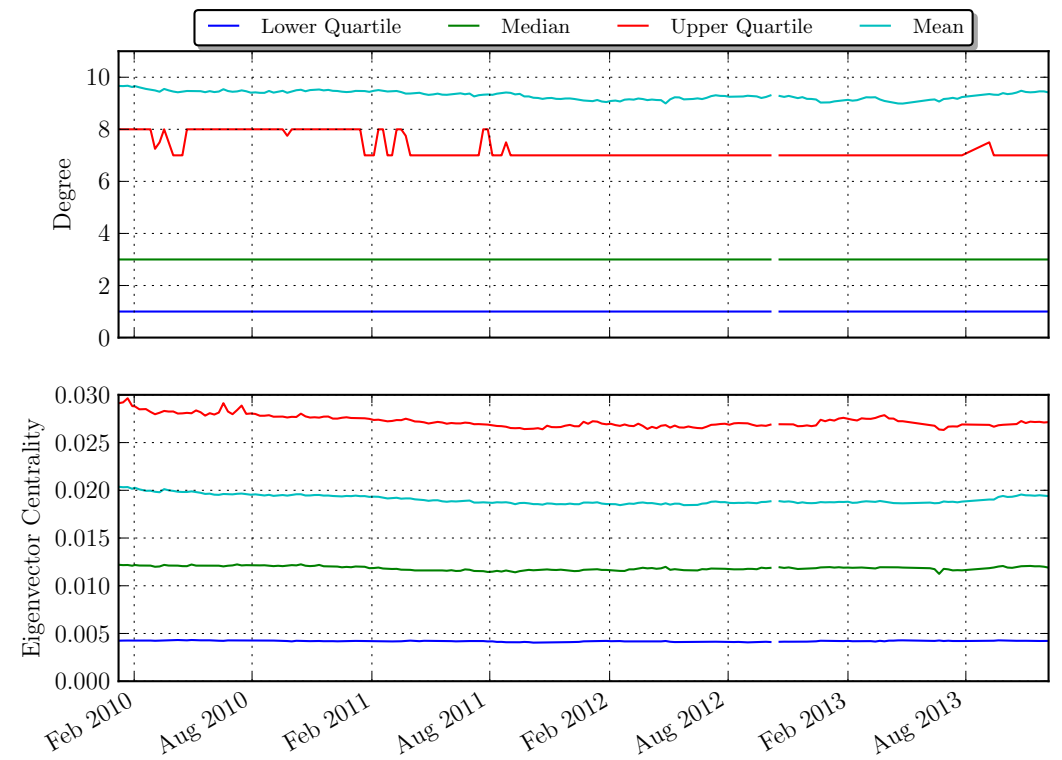

Notes: The top panel of this figure plots statistics summarizing the degree distribution of the counterparty network through time. The bottom panel of this figure plots statistics summarizing the eigenvector centrality distribution of the counterparty network through time. The counterparty network on each day is as defined in Figure 11.

centrality is a measure of the influence of a node, so that nodes that are either very central or connected to very central nodes have a high eigenvector centrality. Like the degree distribution, the eigenvector centrality distribution remains stable through time, indicating that the distribution of node importance is also quite constant.

The dynamics of the overall degree distribution and eigenvector centrality distribution paints an incomplete picture. The reason is that each end users' own network (e.g. the number and identities of dealers they face) is unlikely to change much over time given the fixed costs associated with creating a trading account. Still, the overall distribution statistics of degree and eigenvector centrality presented in Figure 13 will reflect mostly end-users since there are far more end-users than dealers. To this end, the more interesting dynamics likely happen within the counterparty network of dealers alone. For instance, it could be that at the beginning of the sample Dealer A was the important dealer in the market, but this later becomes Dealer B.

Figure 14 therefore explores the potentially dynamic role of dealers in the counterparty network. The main takeaway is that place of each dealer in the network is also basically constant through time. The top panel of 14 shows that the number of connections of each dealer does not change much through the sample; however, there is a slight reordering in terms of which dealer has the most connections around February 2012, with dealer 12 becoming the most connected thereafter. The middle panel of Figure 14 provides evidence that the importance of each, as measured by eigenvector centrality, is also effectively flat through time. The bottom panel of 14 reveals that there is indeed some more variation in the betweenness centrality of each dealer. Still, there is little movement in the top three dealers, as dealers 3, 12, and 15 have the highest betweenness centrality measures throughout the sample. In effect, this means that there 
Figure 14: Counterparty Network Distribution Through Time: Dealers Only

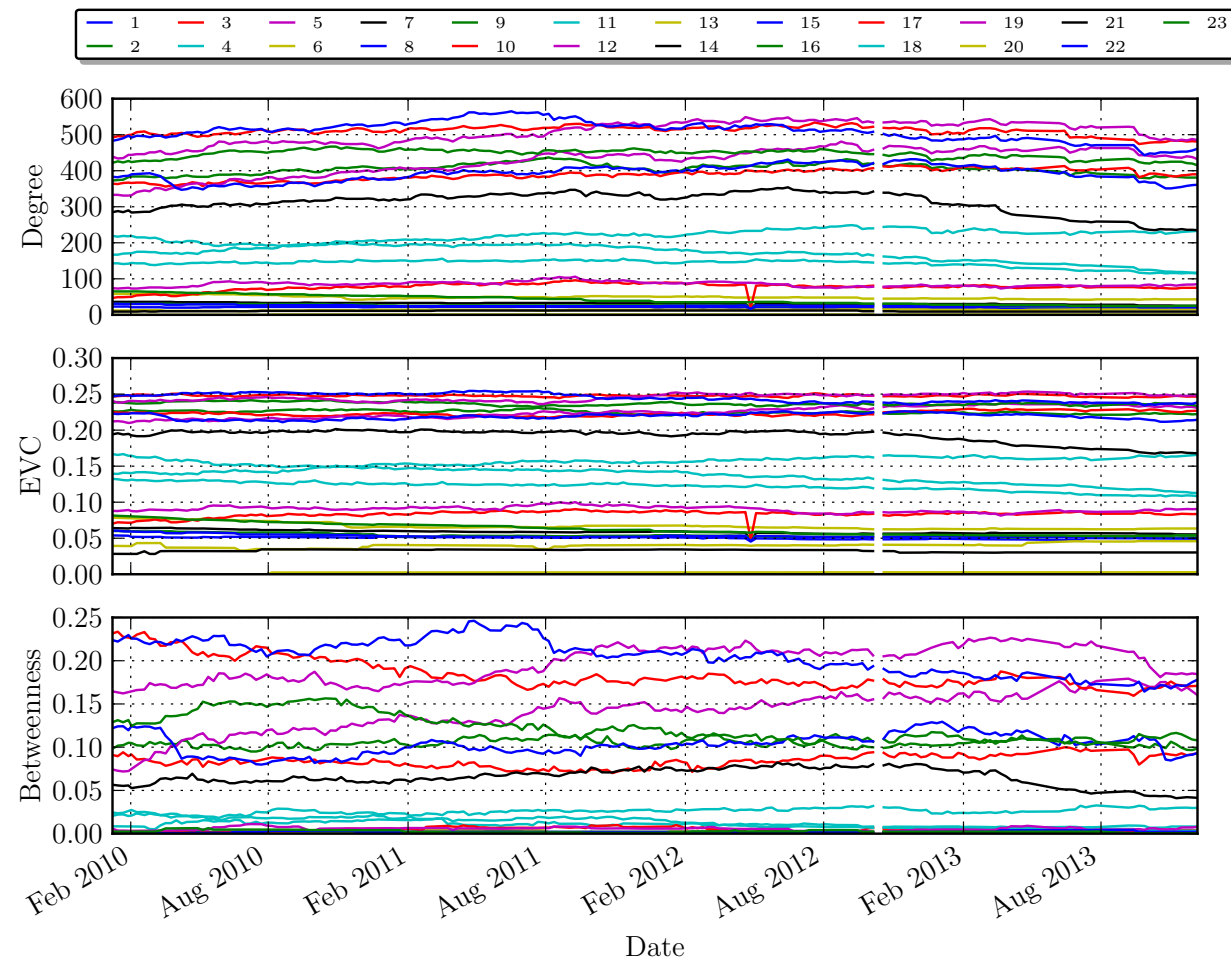

Notes: The top panel of this figure plots the degree of dealers in the counterparty network through time. The middle panel of this figure plots the eigenvector centrality of dealers in the counterparty network through time. Finally, the bottom panel plots the betweenness centrality of dealers in the counterparty network through time. The counterparty network on each day is as defined in Figure 11. 
are consistently three firms through which a majority of the shortest paths within the counterparty network must flow through.

Overall, the main conclusion from the analysis of the dynamics of the counterparty network is that the network is, in fact, not very dynamic. Showing that this counterparty network structure is stable only implies that, for example, the subnetwork of end-users that face (regardless of selling or buying protection) a given dealer does not change through time. Moreover, there are more important dealers in terms of connecting other counterparties in the CDS network, and the identity of these dealers is also constant through time. It is important to realize that the preceding analysis does not speak to how credit risk is actually distributed in this network. Risk flows will be considered in a different network structure in Section 1.6.

\subsection{The Role of Dealers: How Does Credit Risk Get Where Its Going?}

\subsubsection{Defining Two Alternative Networks}

The analysis from the previous sections suggests a large role for dealers in CDS markets. The evidence presented thus far demonstrates that dealers serve two key functions: (i) as pure intermediaries that connect end-users who want to buy and sell CDS and (ii) as ultimate buyers and sellers of credit risk. While the former is not surprising given that CDS is traded OTC, the latter is a new conclusion reached in this paper. Moreover, it is clear that the role of dealers as ultimate sellers of protection dominated at the early part of the sample, but has since diminished somewhat as credit risk has moved outside of the dealer system. In this section, I will therefore focus on the interdealer market for CDS in order to pinpoint how exactly risk flows into this system, but also how it is reallocated once it is inside the dealer network.

There are a number of ways to use graph theory to model risk flows in CDS markets. As it turns out, it will prove useful for my purposes to consider two graphs in conjunction with each other.

A Network Representation of the Entire CDS Market The first representation of risk flows simple captures bilateral net exposures between all counterparties in the economy. Formally, denote the set of all counterparties by $C$. I define a gross bilateral exposure matrix $\mathcal{G}$. An element $\mathcal{G}_{i, j}$ capture the gross amount of protection sold by counterparty $i$ to counterparty $j$ for $i, j \in \mathcal{C}$. For this section, I compute the gross amount of protection sold by summing over all reference entities. One justification for summing over all reference entities is that the credit qualities of most industries are positively correlated. This means that selling protection across two industries is alone unlikely to be a hedged bet. A second justification comes from the results of previous sections, where we saw that the same set of counterparties are responsible for a large proportion of CDS protection selling. ${ }^{13}$.

Once I populate the elements of $\mathcal{G}$, I can easily build a matrix of bilateral net exposures. Define this matrix as $\mathcal{N}$. Elements of the matrix $\mathcal{N}$ are then naturally defined as $\mathcal{N}_{i j}=\max \left(\mathcal{G}_{i j}-\mathcal{G}_{j i}, 0\right)$. Intuitively, if $i$ is a net seller of protection to $j$, then $\mathcal{N}_{i, j}>0$ and $\mathcal{N}_{j, i}=0$. While the network in $\mathcal{N}$ is indeed useful for understanding the CDS market at a broad level, I also propose an alternative categorization that, in effect, zooms in on the dealer network.

\footnotetext{
${ }^{13} \mathrm{~A}$ similar argument holds for the buyers of protection.
} 
A Network Representation of the Interdealer Network To start, I build a weighted and directed network of exposures between counterparties. There are a set of dealers indexed from $d=1, \ldots D$. Motivated by the counterparty network in Section 1.5, each dealer is endowed with a three "end-users": the first enduser encompasses all customers who are net buyers of protection overall, the second is the set of customers who are net sellers overall, and the third represents all exposures with end-users that pass through a central clearing party. I will address the issue of the central clearing party shortly. The identity of dealer $d$ 's end-user is given by $e_{d}^{t}$, for $t \in\{n b, n s, c c p\}$. $e_{d}^{t}$ is meant to collapses all of the bilateral exposures between dealer $d$ and its customers of type $t$ into a single bilateral exposure with one counterparty. For instance, $e_{d}^{n b}$ is set of end-users for dealer $d$ who are net buyers overall.

The total set of counterparties in the marketplace is then $\Omega=\{1, \ldots, D, D+1, \ldots 2 D, \ldots 3 D, \ldots, 4 D\} . \Omega$ is ordered such that dealer $d$ is matched to element $d$ in $\Omega$, $d$ 's end-users who are net buyers are element $D+d, d$ 's end-users who are net sellers are element $2 D+d$, and so forth. The $4 D \times 4 D$ bilateral exposure matrix is denoted by $H$. Analogous to the network in $\mathcal{G}$, the $(i, j)$ element of $H$ is the gross CDS exposure sold, over all reference entities, by counterparty $i$ to counterparty $j$. Consider the first dealer, i.e. $d=1$. By assumption, $H_{i j}, H_{j i}=0$ for all $j \notin\{2, \ldots D, D+1,2 D+1,3 D+1\}$. That is, dealer $d=1$ has bilateral exposures only with other dealers, and her specific end-users. This is not to say that the end-user each dealer faces is unique. Instead, this is a convenient modeling tool that allows me to decompose risk that flows to dealers from end-users versus other dealers. Henceforth, I will refer to $H_{i j}$ as the "outflow" from $i$ to $j$, and the "inflow" to $j$ from $i$.

Like with the network in $\mathcal{N}$, the net amount of protection sold by $i$ to $j$ can be computed easily from $H$. as $\max \left(H_{i j}-H_{j i}, 0\right)$. I refer to this network as $\mathcal{R}$, with $\mathcal{R}_{i j}=\max \left(H_{i j}-H_{j i}, 0\right)$.

Before building a network depiction of the risk flows in CDS markets, I must address one key subtlety. Namely, as a part of the mandates stemming from the financial crisis, there has been a movement towards using a central clearing party $(\mathrm{CCP})$ for CDS trading. In the current context, the goal is to determine how much of the gross flows to and from a dealer come from end-users and from other dealers. When a dealer clears a trade with the CCP, it is therefore crucial to determine how much of the flow from the CCP originates from end-users, and how much originates from other dealers. In Appendix 4, I demonstrate how a few simplifying assumptions and accounting identities present a natural solution to this issue. There are only two assumptions that are required: first, I assume any gross selling from ICE to non-dealers originates from dealers. This assumption derives from the simple observation that non-dealers do not trade directly with non-dealers in the CDS market. ${ }^{14}$ The second assumption is that the proportion of gross buying/selling that flows to any one dealer from non-dealers, but via the CCP, are constant across all dealers at each point in time. Put differently, it means that if Dealer A and Dealer B both have inflows from the CCP, then a proportion $\alpha^{i} \in[0,1]$ of that inflow comes other dealers, and a proportion $\left(1-\alpha^{i}\right)$ comes from nondealers. The constant $\alpha^{i}$ is irrespective of the identity of each dealer. A similar assumption is required when determining what proportion of a single dealer's outflows, $\alpha^{o}$, goes to dealers. I discuss these assumptions in greater detail in Appendix 4; I further argue that because a vast majority of all gross inflows/outflows occur within the dealer network, the assumption of $\alpha^{i}$ and $\alpha^{o}$ being constant across dealers is not empirically

\footnotetext{
${ }^{14}$ For instance, if a Hedge Fund A wants to clear a trade with Dealer D, they first contact each other to initiate the trade. They then go together to the CCP to clear the trade. This type of initiation does not occur between non-dealers and non-dealers. The counterparty network from Section 1.5 confirms this notion, as does extensive conversation with practitioners.
} 
constraining.

As a result, I am able to decompose flows to and from the CCP into (i) flows going/coming from other dealers and (ii) flows going/coming from non-dealers. To incorporate this feature into the network model, I introduce a "new" counterparty, $C C P_{D} . C C P_{D}$ represents the central clearing party, but restricts risk flows that occur exclusively with other dealers. For instance, $H_{i, C C P_{D}}$ is the gross amount that dealer $i$ sells to the $C C P$ that is ultimately passed onto dealers. In turn, $H_{C C P_{D}, i}$ is the gross amount that the $C C P$ sells to dealer $i$ that originates from other dealers. As mentioned above, $H_{i, C C P_{D}}$ and $H_{C C P_{D}, i}$ are calculated as follows:

$$
\begin{aligned}
& H_{i, C C P_{D}}=\alpha_{o} \times \text { gross sold by dealer } i \text { to the CCP } \\
& H_{C C P_{D}, i}=\alpha_{i} \times \text { gross sold to dealer } i \text { by the CCP }
\end{aligned}
$$

To compute the gross amount that dealer $i$ sells to non-dealers via the CCP, I again use the inflow/outflow decomposition:

$$
\begin{aligned}
& H_{i, i+3 D}=\left(1-\alpha_{o}\right) \times \text { gross sold by dealer } i \text { to the CCP } \\
& H_{i+3 D, i}=\left(1-\alpha_{i}\right) \times \text { gross sold to dealer } i \text { by the CCP }
\end{aligned}
$$

With the introduction of $C C P_{D}$, the set of counterparties is now $\widetilde{\Omega}=\Omega \cup\left\{C C P_{D}\right\}$, which means there are a total of $4 D+1$ counterparties being modeled in the system.

\subsubsection{Empirical Results}

I begin by dividing the sample period into two halves. The first half spans from 2010-2012, and covers the period of time where dealers were the primary seller of protection across most reference entities. The second half spans from 2012-2014, and marks the rise of hedge funds/asset managers as a large sellers of credit insurance. To highlight the two regimes, Figure 15 first plots the networks reduced bilateral net exposure network $\mathcal{R}$ (top panel) and economy-wide bilaternal net exposure network $\mathcal{N}$ (bottom panel) in mid-2011. Figure 16 then plots the same two networks at the end of February 2014.

For each plot of the network $\mathcal{R}$, the dealers are arranged around the inner circle that surrounds $C C P_{D}$. Dealers are indexed sequentially, and I also report the net amount sold $(\$ b n)$ by each dealer next to their index. For instance, on $6 / 3 / 2011$, dealer 7 had net sold $\$ 90$ billion in overall protection on U.S. reference entities. The outer ring of nodes represent the end-users for each dealer. The designation of $b$ or $s$ indicate whether the end-user is the collapsed set of customers who are net buyers or net sellers, respectively. Nodes that are white indicate flows via the CCP. The size of each node is proportional to the absolute value of the net overall position, so that large net buyers and large net sellers have bigger nodes. Red nodes represent counterparties who are net sellers overall, and cyan nodes represent counterparties who are net buyers overall. A thicker stub at the edge entering a node indicates that risk is flowing to that stub (i.e. they are net selling to the other node in the edge). For example, dealer 13 is a net buyer of protection from its "net seller end-user" (denoted by $s$ ) for an amount of $\$ 7$ billion on $6 / 3 / 2011$. Finally, the thickness of an edge is proportional to the amount bought/sold between two counterparties.

For each plot of the network $\mathcal{N}$, the size of nodes in this network are again proportional to the absolute 
value of their net overall exposure. Thus, large buyers and large sellers both have large nodes. Net overall sellers have nodes that are one of two different shades of red. Pure red nodes indicate dealers who are net sellers; maroon nodes indicate non-dealers who are net sellers. Similarly, net overall buyers are nodes that are one of two different shades of blue. The lighter blue nodes indicate dealers who are net overall buyers; the turquoise nodes are non-dealers who are net buyers. Finally, the large white node represents the central clearing party.

Before comparing the evolution of the risk networks through time, it is instructive to compare the networks $\mathcal{N}$ and $\mathcal{R}$ within a single period. Let me start with the network $\mathcal{R}$ on $6 / 3 / 2011$ (top panel of Figure 15). Despite $\mathcal{R}$ summarizing exposures over all reference entities, many of the conclusions from Sections 1.2, 1.3, and 1.4.2 are echoed in Figure 15. On 6/3/2011, there are three dealers - three large red nodes - who are very large net sellers of protection overall.As we will see shortly, dealer 16 is the largest net seller of U.S. credit protection among all counterparties; however, a majority of the credit risk that flows to her comes from other dealers, as opposed to her end-users. To see why, notice that absent any positions with other dealers, dealer 16 would have to net sell $\$ 11$ billion in order to meet the demands of her end-users. She sells $\$ 23$ billion to her buyer end-user (including via the CCP), offsets $\$ 12$ billion of that to her seller end-user, and absorbs the imbalance by selling $\$ 11$ billion in protection. Because dealer 16 is a net seller of $\$ 159$ billion overall, it must be the case that she sells $\$ 148$ billion in protection to other dealers.

Dealer 13 similarly has a large portion of its risk inflows coming from other dealers. Dealer 13 has to absorb $\$ 32$ billion of credit risk just to meet his end-users demands. Because he is a net seller of $\$ 96$ billion overall, it must mean that $\$ 64$ billion of risk is flowing to dealer 13 via the other dealers. When U.S. credit risk flows outside of the dealer network, it does so primarily through dealers 2,9 , and 16; these dealers have the largest end-users in terms of net selling. ${ }^{15}$

In terms of counterparties who offload U.S. credit risk via CDS, dealers 2 and 10 are the largest dealers who buy protection on 6/3/2011. Dealer 10 relies heavily on the dealer network to offload credit risk. He sells almost $\$ 35$ billion in protection to his net buyer end-user, but is able to offload only $\$ 7$ billion of this to his net seller end-user. Thus, in order to obtain his $\$ 51$ billion position that is short credit risk, dealer 10 must purchase nearly $\$ 79$ billion in protection from other dealers. Furthermore, the thick band flowing from dealer 5 to $C C P_{D}$ indicates that a lot of his protection is bought from other dealers via the central clearing party.

Many of the same conclusions can be drawn from the network $\mathcal{N}$ in the bottom panel of Figure 15. For instance, dealers 7, 13, and 16 are the three large red nodes located near $(0.5,1),(0,0.42)$, and $(0.17,0.17)$, respectively. Additionally, it is apparent that these three dealers are the largest sellers of protection in the economy at large; whereas the strongest statement that could be made from $\mathcal{R}$ was that these three were the largest sellers of protection within the set of dealers only. The network $\mathcal{N}$ also reveals the presence of an end-user who is a relatively large net seller of protection. This counterparty is located near $(0.35,0)$ in the bottom panel of Figure 15. Why doesn't this counterparty stand out in the network depiction of $\mathcal{R}$ ? The reason is simple, yet subtle. Indeed, no singular end-user in $\mathcal{R}$ (i.e. the nodes on the outer ring) appears as a particularly large net seller. It must therefore be the case that the large net selling end-user in $\mathcal{N}$ spreads her exposures out across multiple dealers, trades with the central clearing party, or some combination of

\footnotetext{
${ }^{15}$ Again, this does not mean these end-users are unique to each dealer. Hedge Fund A, for example, may spread their positions across these dealers. The point of this network depiction is to highlight how risk flows through the dealers to end-users.
} 
Figure 15: CDS Risk Network on 6/3/2011: Top panel is $\mathcal{N}$ and bottom panel is $\mathcal{R}$ 20110603
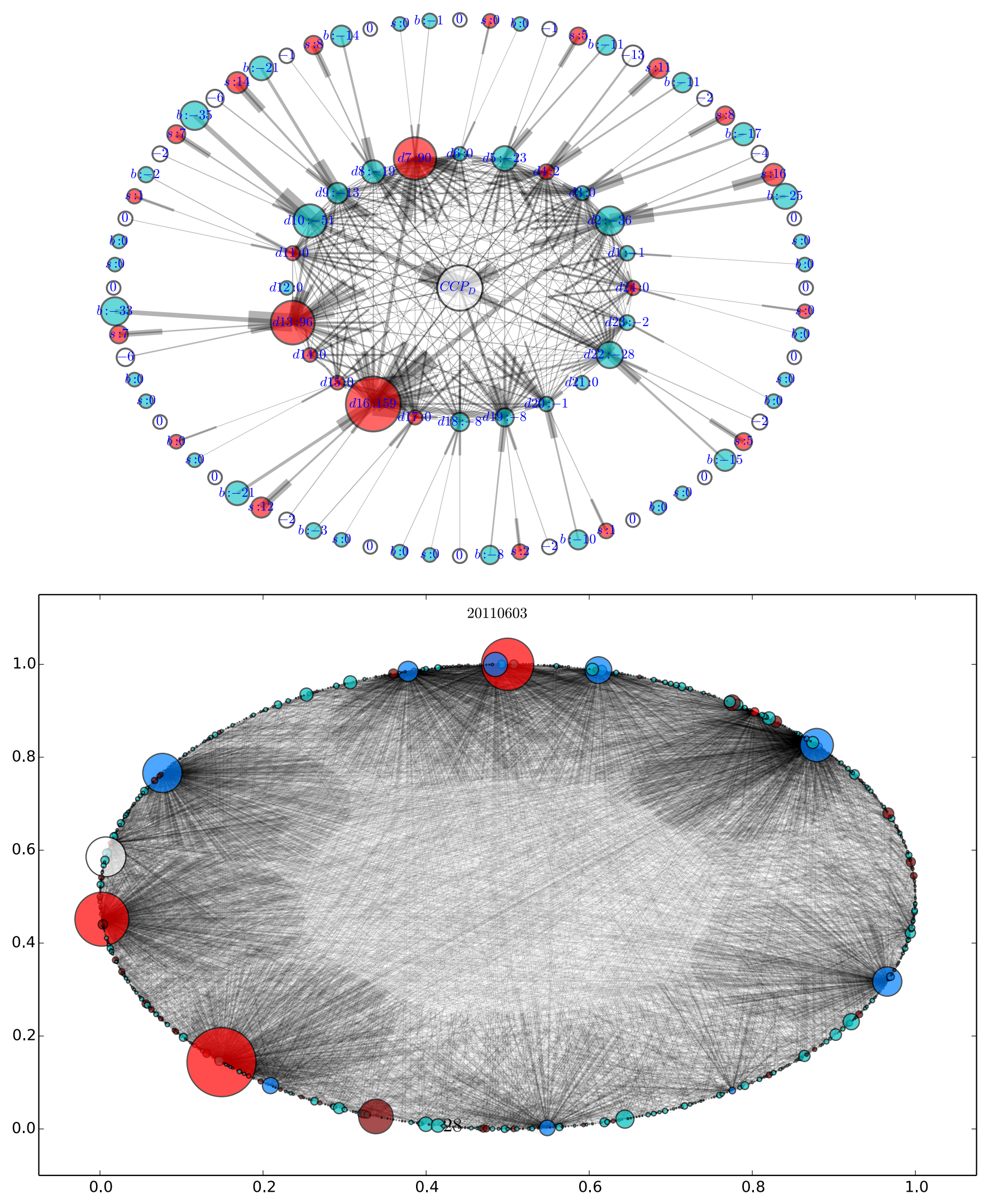
both.

Next, I examine the network $\mathcal{R}$ on $2 / 28 / 2014$ in the top panel of Figure 16 . The picture is quite similar to the network on $6 / 3 / 2011$ with the major exception being that dealer 7 has pushed almost all of its risk to its net seller end-user. There is also an overall reduction in the amount of net selling, which is likely driven by a contraction in the aggregate CDS market.

When studying $\mathcal{N}$ on $2 / 28 / 2014$ (the bottom panel of Figure 16 ), we now see the presence of more end-users who are substantial net sellers, relative to the same picture on $6 / 3 / 2011$. This shift is consistent with the fact that hedge funds/asset managers have become a majority seller across all reference entities. There are two end-users who are particularly large net sellers on this date. The first end-user, located near $(0.8,0.9)$, corresponds to the end-user who absorbed dealer 7 's risk as seen in $\mathcal{R}$ for this date. The second end-user is located near $(0.35,0)$, but still fails to stand out in the network $\mathcal{R}$. As previously discussed, this implies that this particular end-user must spread her trades across dealers and/or clears her trades with the central clearing party. When comparing $\mathcal{N}$ on $6 / 3 / 2011$ and $2 / 28 / 2014$, it is also apparent that the end-user near $(0.35,0)$ has assumed a larger net selling position.

The role of dealers is highlighted by both depictions of the risk network, $\mathcal{R}$ and $\mathcal{N}$; as of $2 / 28 / 2014$, dealers 13 is not only a large absorber of credit risk, but he also facilitates credit risk transfer to customers who are also relatively large absorbers and hedgers of credit risk. On the other hand, dealer 7 has reduced its role as a large bearer of credit risk, but now facilitates the transfer of risk to a large natural seller of protection. A more formal model of optimal risk bearing and risk intermediation is necessary to better understand the whether the risk sharing environment CDS markets is optimal. In other words, is it optimal to have the large bearers of credit risk also be responsible for connecting the rest of the economy to large bearers of credit risk? Perhaps this is a worthwhile modeling topic for future research.

\section{Appendix: A Discussion of Prime-Brokerage Services}

A potential complication to my conclusion is the prime-brokerage services that parent companies of dealers provide to their clients. Examples of prime-brokerage services include centralized margining, basic custodial services, and risk management advisory services. Whether prime-brokerage activities confound the results of the paper rests crucially on how brokerage services play out in CDS markets. Suppose Dealer A is also the prime-broker for Hedge Fund X, and Hedge Fund X wants to sell $\$ 100$ of protection on GE. Moreover, Dealer A has found a second Hedge Fund Y who wants to buy $\$ 100$ of protection.

Prime-Brokers Trade With Clients If prime-brokers trade with clients, then it means they contractually take the other side of client trades. In this example, this means that I observe two transactions. In the first, Dealer A buys $\$ 100$ of protection from Hedge Fund X. In the second, Dealer A sells $\$ 100$ of protection to Hedge Fund Y. The credit risk is passed from Hedge Fund Y to Hedge Fund X, and Dealer A correctly appears to have zero exposure.

According to the DTCC, this is the primary way in which prime-brokerage services operate in CDS markets. ${ }^{16}$ The legal agreement between the prime-broker and the client is typically called a "give-up" agreement. Normally, a client has an agreement with their prime-broker that the client can execute trades

\footnotetext{
${ }^{16}$ Thank you to Chris Mullen of the DTCC for a very helpful discussion on these issues.
} 
Figure 16: CDS Risk Network 2/28/2014: Top panel is $\mathcal{R}$ and bottom panel is $\mathcal{N}$

20140228
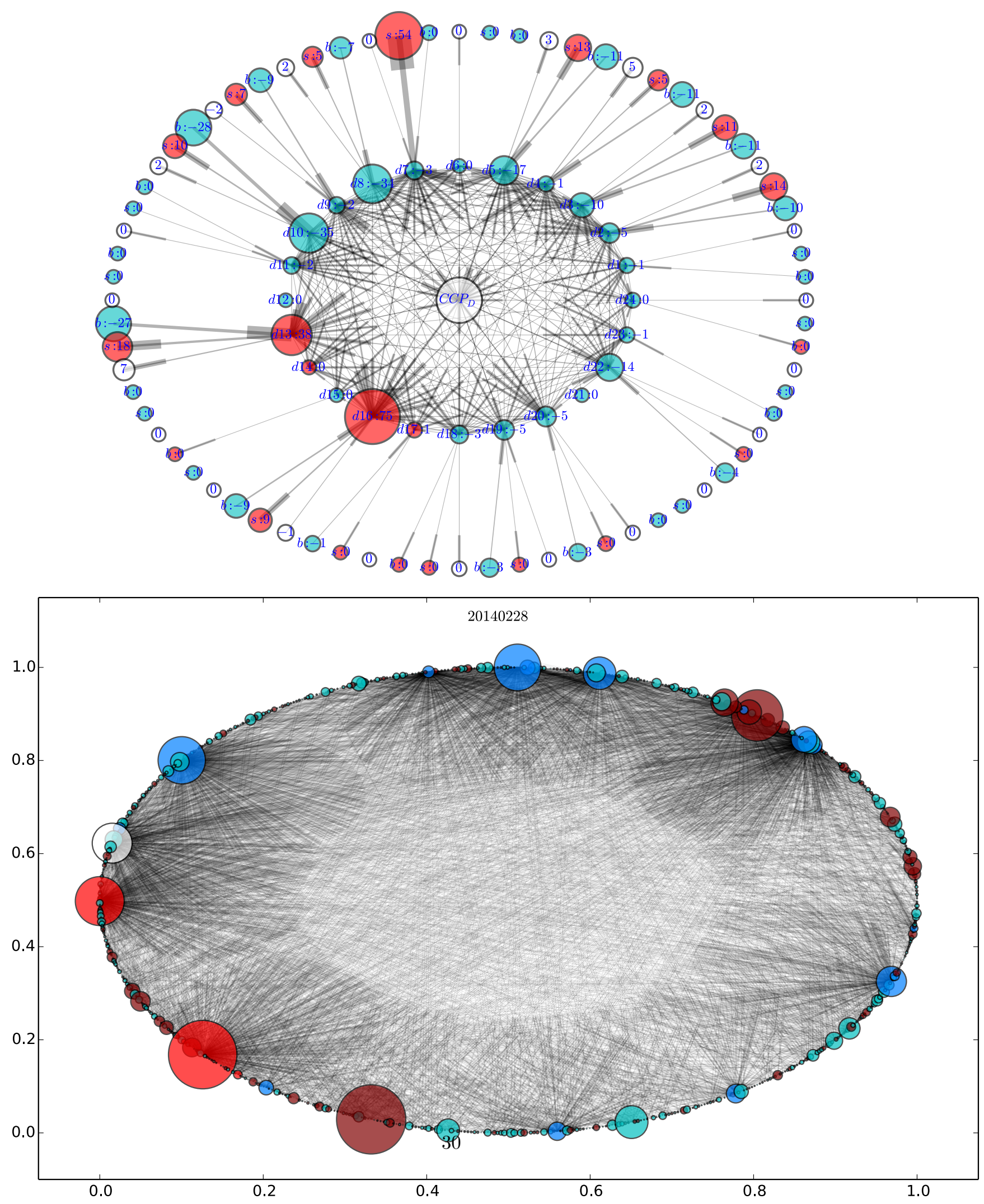
with a preset group of other dealers. The give-up arrangement means that, upon a trade being executed between the client and the dealer (not the prime-broker), the client will give-up the trade to their prime broker. Legally, two transactions occur, with the prime-broker trading with the dealer and the prime-broker trading with their client.

The net position of the prime-broker in this case is zero. The client is keen to have these give-up arrangements in place because they centralize trade processing with their prime broker, and they have the ability to face multiple dealers. The prime broker is properly incentivised because they earn fees from their clients for providing this service. Finally, the other dealers happily accept this legal arrangement because they get volume from the client; from a counterparty risk standpoint, they also only face the prime broker, who is usually less risky than smaller clients (e.g. hedge funds).

Importantly, this means that all net positions I observe in my database are true economic exposures. That is, it is not the case that I observe a prime broker trading on behalf of their client, so that it appears that the prime broker is taking a position, but in reality the position is fully backed by a "hidden" client.

\section{Definition of Network Statistics}

In this appendix, I provide definitions for the network statistics used in the main text. Many of the definitions here borrow from Jackson (2012) and the lecture notes on networks found on Daron Acemoglu's website. ${ }^{17}$.

\subsection{Undirected and Unweighted Network Statistics}

The basic ingredients for a undirected and unweighted network are a graph $(N, E) . N=\{1, \ldots, n\}$ represents the nodes in the network, and $E$ is an $n \times n$ matrix representing the edges of the network. An element $E_{i j} \in\{0,1\}$ indicates the absence $\left(E_{i j}=0\right)$ or presence $\left(E_{i j}=1\right)$ of a connection between node $i$ and node $j$.

- Node Degree: The degree of node $i$ is given by $\sum_{j \neq i} E_{i j}=\sum_{j \neq i} E_{j i}$

- Network Diameter: Define a geodesic as the shortest path between any two nodes, and its length as $I(i, j)$. Then the diameter of a graph or network is $\max _{i, j} I(i, j)$

- Betweenness Centrality: Let $P_{i}(k j)$ denote the number of geodesics paths between $k$ and $j$ that $i$ lies on. Further, let $P(k j)$ be the total number of geodesics between $k$ and $j$. Betweenness centrality is defined as:

$$
B C_{i}(E)=\sum_{k \neq j: i \notin\{k, j\}} \frac{P_{i}(k j) / P(k j)}{(n-1)(n-2) / 2}
$$

- Eigenvector Centrality: The eigenvector centrality of each node is contained in the eigenvector corresponding to the largest eigenvalue of $E$

\footnotetext{
${ }^{17} \mathrm{http}: / /$ economics.mit.edu/faculty/acemoglu/courses
} 


\section{Rule of Thumb for Flows from ICE}

The purpose of this appendix is to propose a way to, for each dealer, decompose flows from ICE into a portion origination from dealers, and a portion origination from non-dealers. The methodology can be applied at any point in time, so I omit references to time. The notation I use is then as follows:

- There are a set of dealers $d=1, . ., D$

- I collapse all non-dealers into one counterparty, denoted non-dealer.

- $S_{i j}$ is the gross amount sold by $i$ to $j$. I further call $S_{i j}$ the "outflow" from $i$ to $j . S_{j i}$ is then the "inflow" to $i$ from $j$.

- Thus, $S_{i j}-S_{j i}$ is the net amount sold by $i$ to $j$

- $j=I C E$ means the counterparty is ICE

- (A1) $\alpha_{d}^{i}$ is the proportion of the inflow from ICE to dealer $d$ that originates from dealers. $\left(1-\alpha_{d}^{i}\right)$ is therefore the proportion of inflow from $I C E$ to dealer $d$ that originates from non-dealers

- (A2) $\alpha_{d}^{o}$ is the proportion of the outflows from dealer $d$ that passes through ICE and ultimately flows to dealers. $\left(1-\alpha_{d}^{o}\right)$ is therefore the proportion of the outflows from dealer $d$ that passes through ICE and ultimately flows to non-dealers.

The gross amount of inflow to dealer $d$ that originates from dealers, but flows through ICE first is then:

$$
\alpha_{d}^{i} S_{I C E, d}
$$

Similarly, the gross amount of outflow from dealer $d$ that will go to dealers is:

$$
\alpha_{d}^{o} S_{d, I C E}
$$

The next assumption is symmetrical: (i) the amount of inflow to ICE from non-dealers must equal the amount of outflow from ICE to dealers, that originates from non-dealers, and (ii) the amount of outflow from dealers to ICE that is intended for non-dealers must equal the amount of outflow from ICE to non-dealers. This is because we know that non-dealers and non-dealers never face each other.

Two equations take shape from this observation, plus assumptions (A1) and (A2) . The first equation simply states that the outflow from ICE to dealers must equal the outflow from non-dealers to ICE plus the outflow from dealers to ICE that is intended for dealers. Formally this means:

$$
\sum_{d=1}^{D} \alpha_{d}^{o} S_{d, I C E}+S_{N D, I C E}=\sum_{d=1}^{D} S_{I C E, d}
$$

The first term on the LHS is the outflow from dealers to ICE that eventually flows to dealers. The second term on the LHS is the outflow from non-dealers to ICE, which again I assume goes exclusively to dealers. The RHS is simply the total outflow from ICE to dealers. 
The second equation analogously states that the outflow from dealers to ICE must equal the outflow from ICE to dealers that originates from dealers plus the outflow from ICE that goes to non-dealers. Mathematically, this yields:

$$
\sum_{d=1}^{D} S_{d, I C E}=\sum_{d=1}^{D} \alpha_{d}^{i} S_{I C E, d}+S_{I C E, N D}
$$

The LHS is the total outflow from dealers to ICE. The first term on the RHS is the outflow from ICE to dealers, that originates from dealers. The last term on the RHS is the outflow from ICE to non-dealers. Because non-dealers do not transact with non-dealers, we know that any inflow to ICE from dealers must go to either dealers or non-dealers.

Equations (9) and (10) also imply that ICE must be net zero. To see why, first sum the two equations:

$$
\sum_{d=1}^{D} \alpha_{d}^{o} S_{d, I C E}+\sum_{d=1}^{D} S_{d, I C E}+S_{N D, I C E}=\sum_{d=1}^{D} S_{I C E, d}+S_{I C E, N D}+\sum_{d=1}^{D} \alpha_{d}^{i} S_{I C E, d}
$$

Then notice that the following holds true by definition:

$$
\sum_{d=1}^{D} \alpha_{d}^{o} S_{d, I C E}=\sum_{d=1}^{D} \alpha_{d}^{i} S_{I C E, d}
$$

since the both sides of the equation represent the total amount that flows from dealers to ICE back to dealers. Finally, Equation (11) reduces to:

$$
\sum_{d=1}^{D} S_{d, I C E}+S_{N D, I C E}=\sum_{d=1}^{D} S_{I C E, d}+S_{I C E, N D}
$$

The LHS of Equation (12) is the total amount of inflows into ICE, and the RHS is the total amount of outflows to ICE.

Equations (9) and (10) are effectively resource constraints. Any set of weights, $\left\{\alpha_{d}^{k}\right\}_{d=1}^{D}$ for $k \in\{o, i\}$ that satisfies this resource constraint is feasible. For simplicity, I assume that $\alpha_{d}^{i}=\alpha^{i}$ is constant across dealers. Similarly, I assume that $\alpha_{d}^{o}=\alpha^{o}$ is constant across dealers. In this case, it is easy to solve (each period) for the proportion of ICE inflows that originates from dealers, as well as the proportion of a dealer's outflows that goes to other dealers:

$$
\begin{aligned}
\alpha^{i} & =\frac{\sum_{d=1}^{D} S_{d, I C E}-S_{I C E, N D}}{\sum_{d=1}^{D} S_{I C E, d}} \\
\alpha^{o} & =\frac{\sum_{d=1}^{D} S_{I C E, d}-S_{N D, I C E}}{\sum_{d=1}^{D} S_{d, I C E}}
\end{aligned}
$$

Of course, there are a number of reasons to believe that $\alpha_{d}$ will be different across dealers. From casual inspection of the data, the inflows and outflows to ICE dominate non-dealer outflows/inflows, so there is unlikely to be substantial heterogeneity in the true $\alpha_{d}^{i}$ and $\alpha_{d}^{o}$. I conclude assuming these variables are constant across dealers (within a period) is innocuous for my purposes. 